\title{
Optimal design of solar assisted industrial processes considering heat pumping: case study of a dairy
}

\author{
Anna S. Wallerand ${ }^{\mathrm{a}, *}$, Maziar Kermani $^{\mathrm{a}}$, Régis Voillata $^{\mathrm{a}}$, Ivan Kantor ${ }^{\mathrm{a}}$, François Maréchal $^{\mathrm{a}}$ \\ ${ }^{a}$ École Polytechnique Fédéral de Lausanne (EPFL) Valais Wallis, Switzerland
}

\begin{abstract}
5 Abstract
6 Pinch analysis and Mixed Integer Linear Programming (MILP) have been extensively studied for optimiza7 tion of industrial processes addressing heat recovery, utility selection and sizing. Analysis of renewable \& utility integration, such as solar thermal or photovoltaics, introduces several obstacles for established methods: the time-dependency of resources, storage inertia and losses, and intrinsic non-linearities of the system performance are difficult to represent by linearized, time-invariant MILP equations. Moreover, waste heat recovery options such as heat pumping cannot be neglected as a potential competitor to solar heat.

This work presents a set of multi-period MILP equations for solar technologies as well as a superstructure for optimization of heat pump cycles. Additionally, a methodology is proposed and applied to simultaneously optimize the process' refrigeration and renewable utility system using $\varepsilon$-constrained parametric optimization. The proposed methodology is illustrated on the basis of a dairy plant for which the different utility technologies are compared and evaluated based on economic and environmental criteria.

It is illustrated that integration of solar energy can contribute to strongly reduce the environmental impact of the process (65 - 75\% reduction in $\mathrm{CO}_{2}$ equivalent emissions), but only in combination with heat recovery $(27 \%)$ and an improved heat pump system $(33 \%)$. Heat recovery and heat pump placement for industrial processes are hereby shown to reduce exergy destruction and total costs and increase energy efficiency in the system by means of thermo-economic optimization. The solutions show that investment in solar energy can be economically and environmentally attractive for industrial processes by considering the whole system and ensuring that solar energy is optimally integrated and utilized.
\end{abstract}

Keywords: multi-period MILP, $\varepsilon$-constraint optimization, heat pump superstructure, flat plate thermal collectors, photovoltaics, thermal storage

\section{Introduction}

Within 90 minutes, enough solar radiation reaches Earth's surface to fulfill the total global primary energy demand of one year [1]. This illustrates the enormous potential related to solar energy which is virtually inexhaustible, abundant, and carbon-neutral if gray energy of the conversion equipment is disregarded. Photovoltaic and solar thermal collectors are widely employed and tested (for warm water, heating and electricity production) in the urban sector; however, application in the industrial sector is still scarce 2 . Although the potential has been extensively proven [3, 4], implementation of solar energy in industrial processes is constrained by several obstacles. Identification of the best point of integration is not trivial and should comply with the process specific thermodynamic and technical constraints related to e.g. the heat exchange equipment [3, [5].

One important point which is often neglected is that integration of more efficient or less emitting heating sources (such as solar thermal) should always be compared to other process optimization measures. Process

\footnotetext{
* Corresponding author

Email address: anna.walleran@epfl.ch (Anna S. Wallerand)
} 
integration is a first step in capitalizing the maximum heat recovery potential together with retrofitting of the heat exchanger network. Beyond this, further measures are possible such as optimization of the operating points of the available utility equipment (e.g. the temperatures of the refrigeration system), mechanical vapor re-compression (MVR), or integration of closed cycle heat pumps.

Heat pump systems (including refrigeration) allow valorization of low-temperature waste heat and thereby improve the process energy efficiency. Optimization of industrial heat pumps has been addressed by various authors. Shelton and Grossmann [6, 7] proposed a mixed integer linear programming (MILP) model for optimization of flexible heat pump superstructures which complies with the general process integration methodology presented by Papoulias and Grossmann [8 10. They define all possible connections of refrigeration stages with the drawback of high complexity for problems with many temperature levels. Other authors based their formulation in the linear domain 11 14. While more recent work dealt with exergy analysis of heat pumps and Mixed Integer Nonlinear Programming (MINLP) [15, 16. None of these works have dealt with solar utility integration.

Optimization of a refrigeration and heat pump system for a dairy plant has been investigated by Becker et al. 17, 18, without the presentation of a flexible superstructure containing a variable number of stages, mixing, and various temperature levels.

Maréchal et al. 19] proposed a multi-period process integration approach that allows utility targeting and optimization of process heat recovery systems during multiple operating periods. Different authors have dealt with the problem of clustering meteorological or energetic data into smaller sets [20, 21] demonstrating that data clustering reduces the computational effort while maintaining a desired accuracy.

Solar integration with industrial processes by means of pinch analysis was addressed by several authors 2, 22, 25. In all cases the importance of process integration and pinch analysis for solar utility integration was considered. However, the time-variance of solar radiation and the related effect on the solar system performance as well as the influence of storage was often simplified or even neglected during the design phase. Furthermore, other process optimization techniques such as heat pumping were completely or partially disregarded.

The main gaps identified in the current literature were the lack of a comprehensive approach for solar process integration which encompasses: (a) multi-period solar utility and storage modeling, (b) process integration techniques, while additionally (c) exploring process optimization tools, such as an improvement of the heat pumping system. Therefore, a step-by-step approach is proposed to overcome some of the identified gaps. The main goal is to account for the influence of meteorological time-variance on the solar collector performance and the impact of storage during the design process while respecting the importance of heat pumping as process optimization measure. A comprehensive method for simultaneous solar design and process refrigeration system optimization is presented of which the innovative aspects are summarized in the following points:

- A multi-period MILP approach is chosen, which has been applied by other authors [19, 21, 25, but is extended to account for the specific characteristics of solar utilities and contains $\varepsilon$-constraints.

- A novel heat pump superstructure presented in [26] is applied for optimal design of multiple stage heat pump cycles.

- The meteorological data is clustered based on common clustering algorithms [27] by proposing a new performance indicator.

- Solar performance calculations are based on state-of-the-art correlations and data from independent testing facilities and producers.

\section{Methodology}

A sketch of the applied methodology is presented in Figure 1. The work is employed in a computational framework which is based on the Lua [28] programming language. It is separated into three main steps: (A) data collection, (B) system resolution, and (C) performance calculation.

(A) Data collection. During the data collection phase, utility and process data are gathered, the energy and mass balances are formulated, and the thermodynamic models are developed. In a preliminary 
step the meteorological data are clustered to form a set of typical days such that the problem size can be reduced from a typical meteorological year (TMY) composed of 8760 hours to a much smaller set (of a few hundred hours). This part of the procedure is presented in Section 2.1.

(B) System resolution. The system resolution aims at targeting different utility designs by solving the multi-period MILP for minimum total annual cost subject to the heat cascade constraints. The general formulation of the multi-period MILP can be found in Section 2.2. During the multi-period MILP a singleobjective optimization is performed with the objective of minimizing the total annual cost. To compare the different scenarios under equal boundary conditions, an $\varepsilon$-constraint is introduced to limit the $\mathrm{CO}_{2}$-equivalent emissions for a set of values.

(C) Performance calculation. Since the results of step (B) are based on linearized equations, it is necessary to recalculate some indicators that are more realistically described by non-linear relations such as the investment cost. Other performance indicators such Carnot efficiency are derived during this step. The respective equations are presented in Section 2.3 .

(*) Scenario definition \& parameter selection. Different utility scenarios are studied by activating or deactivating the respective integer variables. These scenarios are evaluated based both on cost and emissions for a continuous $(24 / 7)$ process operation and a daytime only scheme. The different cases are presented in Section 3.1

\subsection{Data collection \& clustering (A)}

This step includes utility and process data gathering, meteorological data clustering, energy and mass balances formulation, and thermodynamic model development.

\subsubsection{Process and utility modeling}

A flowsheet of the process case study and proposed utility system is presented in Figure 2, The units marked in black (boiler, and ammonia refrigeration cycle) are the utilities in place. Units indicated with an asterisk $\left(^{*}\right)$ are newly added in this study (mainly the heat pump superstructure and solar utilities).

Process. The analyzed dairy plant is modeled as a retrofit problem, it transforms raw milk into concentrated milk, pasteurized milk and cream, yogurt, and dessert. Due to various outputs, specific heat requirements will always be provided with respect to the raw milk inlet. The process requires heating (up to $98^{\circ} \mathrm{C}$ ) and cooling (down to $4^{\circ} \mathrm{C}$ ), which in the original plant is provided by a boiler and an ammonia refrigeration cycle. Heating is conveyed through steam and cooling through a water glycol mixture (from the refrigeration) or cooling water. The original process energy requirements are $2.1 \mathrm{MW}_{\mathrm{th}}$ of heat and $167 \mathrm{~kW}$ el of electricity (from the refrigeration cycle) for a raw material consumption of $10 \mathrm{~kg} / \mathrm{s}$.

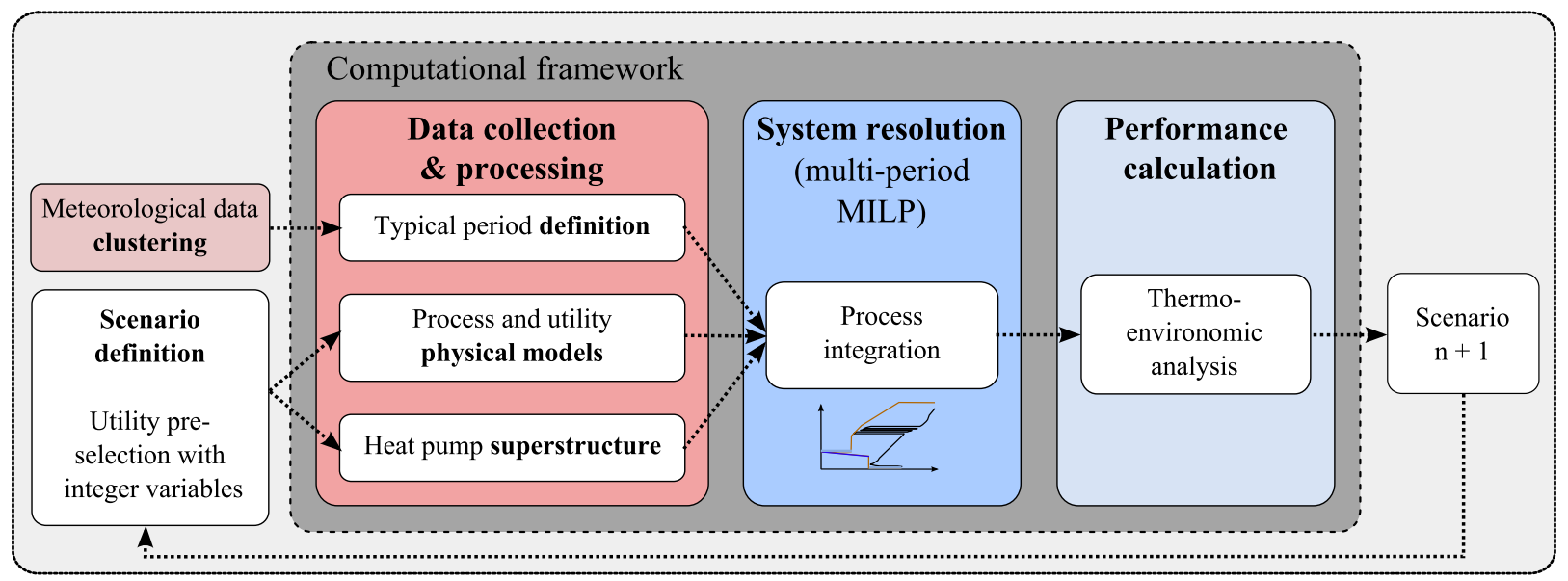

Figure 1: Methodology applied in this study. 
Figure 3 depicts the process composite curves. The three evaporation stages of the concentrated milk production create a clear process pinch point at $59^{\circ} \mathrm{C}$. The highest temperature heat requirement is slightly below $100^{\circ} \mathrm{C}$. The hot minimum energy requirement, $\mathrm{MER}_{\text {hot }}$, is $1.6 \mathrm{MW}_{\text {th }}$ and the $\mathrm{MER}_{\text {cold }}$ lies at 0.8 $\mathrm{MW}_{\mathrm{th}}$. Through process integration (maximum heat recovery) the hot utility requirement can be reduced by $24 \%$ (compared to $2.1 \mathrm{MW}_{\mathrm{th}}$ ).

The plant is positioned in Switzerland and the process heat requirements are taken as constant during its operation. This could eventually be refined by considering shifted operation schedules of different units throughout a working day, but is currently not considered. A full list of process streams is provided in Appendix E The dairy plant was originally modeled by Becker et al. 17, 18, who proposed options for reduction of $\mathrm{CO}_{2}$-emissions with mechanical vapor re-compression and heating with a co-generation engine. In this study, the referenced work is expanded by evaluation of a flexible heat pump superstructure comprising various pressure levels and allowing to optimize the refrigeration system, in addition to analysis of the potential for time-variant solar utility integration.

Two process operating schedules are investigated:

- daytime only operation (7h/day, $2625 \mathrm{~h} /$ year $), \Delta$

- continuous (8760h/year), O

Boiler (BOI). It is assumed that the boiler is already installed in the industrial retrofit problem. Therefore, there is no capital cost associated with the use of the boiler. The boiler is activated in all scenarios as back-up utility. It relies on natural gas combustion and therefore generates $\mathrm{CO}_{2}$-emissions when in operation. Partload performance is neglected. All respective modeling equations and input data are specified in Appendix B.2

Flat plate collector (FP). Single glazing flat plate thermal collectors are modeled according to available performance data of independent testing facilities (such as the Institut für Solartechnik, (SPF) 29]) with solar keymark [30 status. The provided test parameters comply with the European norm for efficiency measurements of thermal collectors EN-12975. Flat plate thermal collectors produce heat up to approximately $130^{\circ} \mathrm{C}$. However, efficiency decreases with higher operating temperatures due to heat losses.

Therefore, the operating temperature range is fit to the dairy process demand which is between 80 and $105^{\circ} \mathrm{C}$. The collector working fluid is a water glycol mixture. The efficiency is further dependent on the intensity of the incoming radiation and its direction. All respective performance equations and input data are presented in Appendix C.1.

Photovoltaic module $(P V)$. High efficiency mono-crystalline photovoltaic modules were considered during the calculation. The modeled energetic output was based on certified producer data (IEC 61215, IEC 61730, 31 taken from the 10th year of operation. The two main parameters influencing the PV performance are the cell temperature (dependent on the ambient temperature, the incident radiation, and the wind speed) and the irradiation intensity. All relevant equations and a performance analysis are presented in Appendix C.2.

Photovoltaic and thermal (HCPVT). The high concentration photovoltaic and thermal system is a concentrating dish (with concentrations of up to 2000 at the focal point) with two axis tracking of the sun which is mounted on a tower. Electricity is generated with photovoltaic cells in the receiver positioned in the focal point. Highly efficient cooling prevents receiver and photovoltaic cell overheating and provides useful heat around $100^{\circ} \mathrm{C}$. Thereby the exergetic losses of the photovoltaic conversion are recovered. High concentration devices can only convert direct beam radiation. Performance indicators are retrieved from producer data [32 35. All modeling equations are depicted in Appendix C.3.

Thermal storage tank $(S)$. The thermal storage mass and energy balances are formulated based on the assumption of sensible heat storage at different temperature levels modeled one tank operating between two temperatures. An intra-cyclic constraint is introduced, which ensures that the storage is always at initial conditions at the end of each day. Furthermore, it is defined (in agreement with a real storage tank with two outlets) that the fluid leaving the storage tank is always at the lowest temperature (bottom) during 


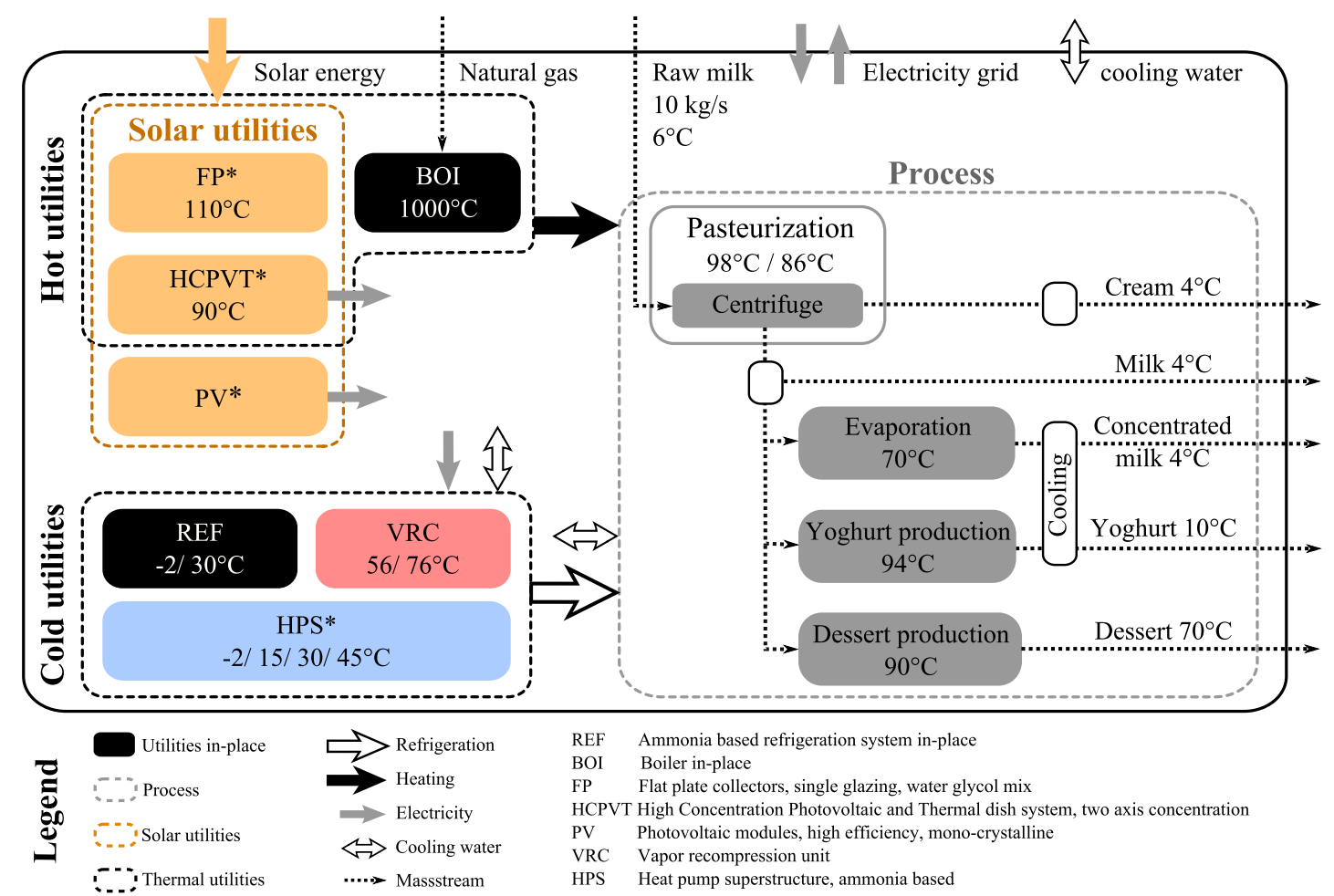

Figure 2: Process flowsheet including utility system. Marked in black are the utilities that are currently in place. Units with $\left.{ }^{*}\right)$ are newly added in this study.
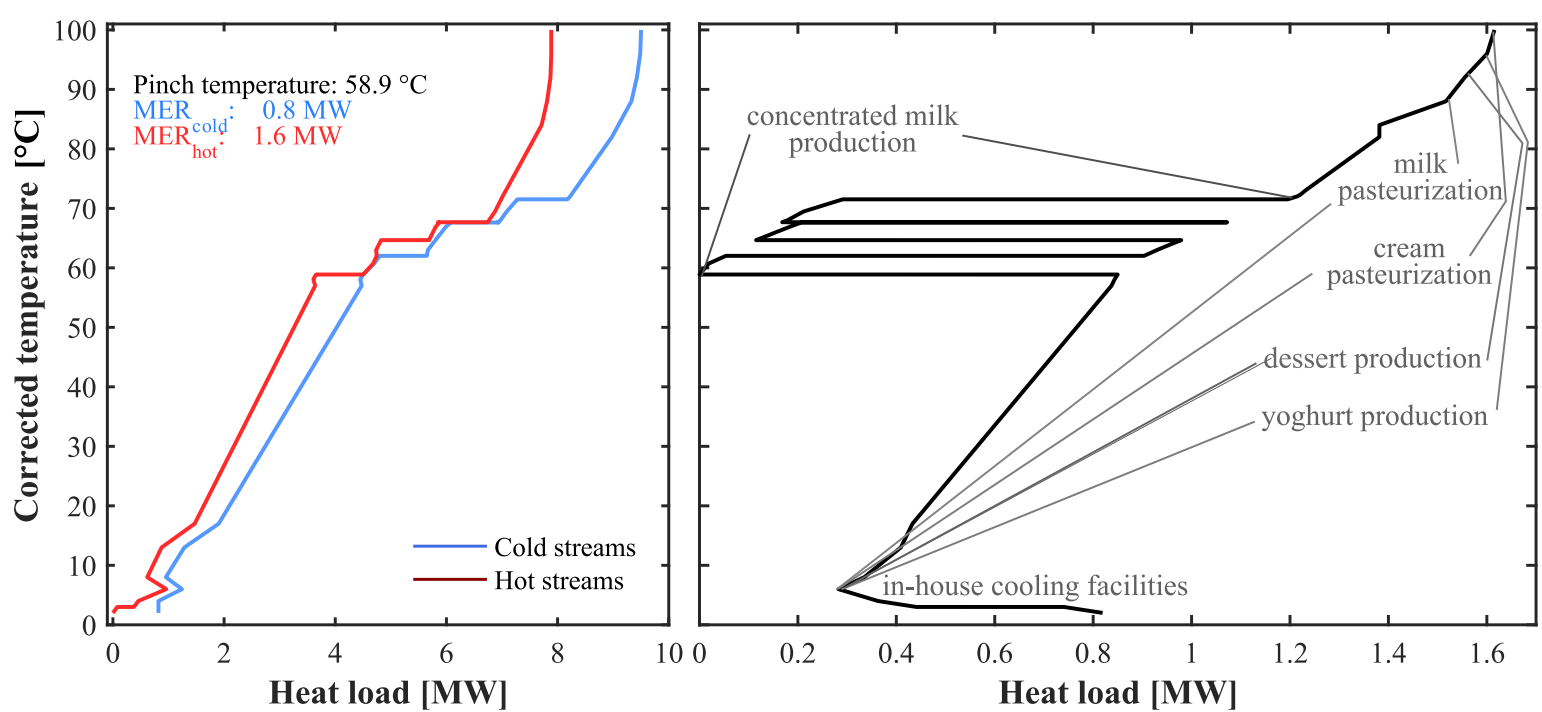

Figure 3: Hot and cold composite curves and grand composite curve of dairy process reproduced from Becker et al. [18] for raw milk inlet of $10 \mathrm{~kg} / \mathrm{s}$. 
charge periods or highest temperature (top) during discharge periods. More information on the storage tank considered can be found in Appendix C.4.

Limitations. The performance of the three respective solar systems is modeled for one piece of equipment. Industrial applications require large collector fields and, therefore, a constant loss factor is introduced in this work to account for thermal and transmission losses in the field. This factor, in reality, scales with the field size and follows certain power laws. Additionally, the impact of shading on the overall output is nonnegligible especially for the tracking systems considering the space is usually limited which is not accounted for either. It is planned to explore the validity of these simplifications by further in-depth analysis in future work.

Heat pump superstructure (REF, MVR, HPS). A superstructure is employed which permits investigation of possible combinations between different heat pump components: compressors, evaporators, condensers, and presaturators 26 .

For selecting the optimal heat pump structure, a set of pressure levels must be defined. The active levels are selected during the system resolution with help of integer variables. The choices are only constrained by the fact that the highest pressure level must be a condenser and the lowest level needs to be an evaporator. Since the pressures and respective temperature levels are chosen in advance, the sizing of the components can be formulated by linear constraints as part of the MILP. Figure 4(a) presents a temperature entropy diagram to illustrate the problem definition, formulating all generic heat pump cycles after the pressure levels are selected. Figure 4(b) shows a flow chart of the superstructure. Connections between all pressure levels are defined as well as potential presaturation, evaporation, and condensation units on every level.

This permits the generation of all possible single and multi-stage cycles between a predefined set of pressure levels. The one-stage refrigeration cycle in place, the vapor re-compression system as well as the improved multi-stage heat pump cycle are modeled with this superstructure. The performance equations as well as all investigated specifications are presented in Appendix B.3

\subsubsection{Meteorological data clustering}

Meteorological data. Weather data including the solar angles (azimuth and elevation), wind speed, ambient temperature, and global horizontal (GHI) and direct normal (DNI) irradiance of hourly time resolution is retrieved from a commercial software (Meteonorm 7.0 [36]). The analysis is carried out for the Swiss city of Sion, having comparably high yearly solar irradiance (GHI 1430, DNI $1690 \mathrm{kWh} / \mathrm{m}^{2}$ ) relative to the rest of the country $\left(1200 \mathrm{kWh} / \mathrm{m}^{2}\right)$ due to a favorable micro-climate.
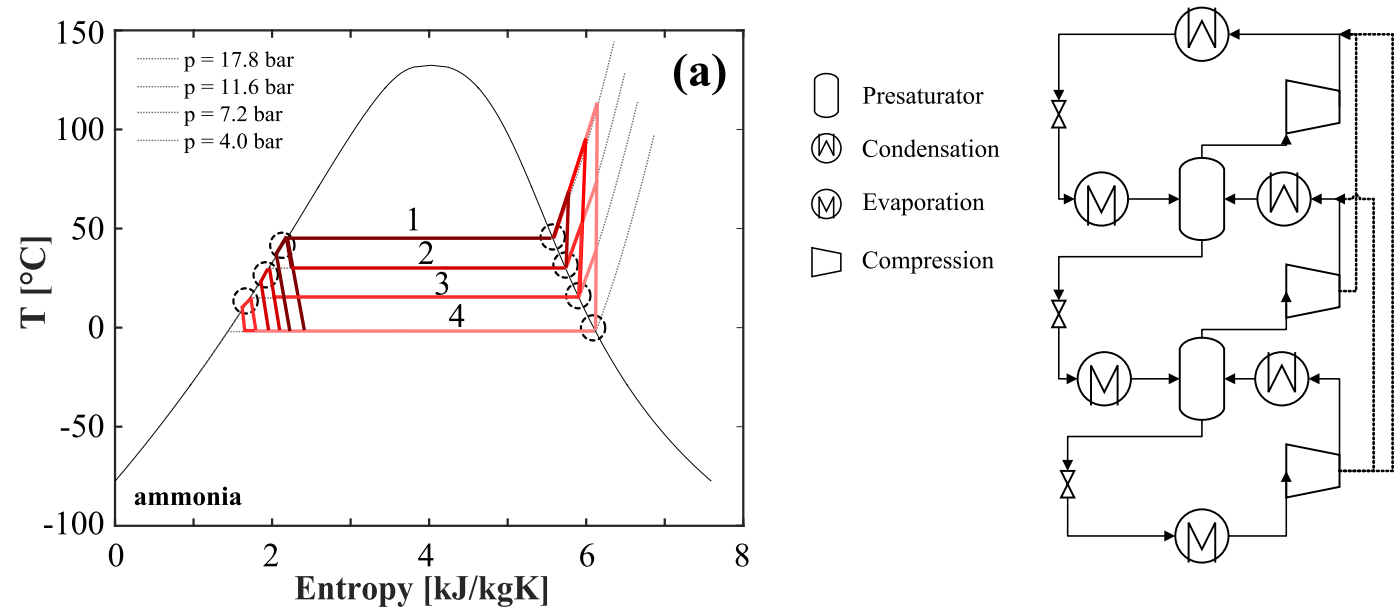

(b)

Figure 4: (a) Ammonia liquid-vapor saturation curve with isobars, (b) heat pump superstructure. 


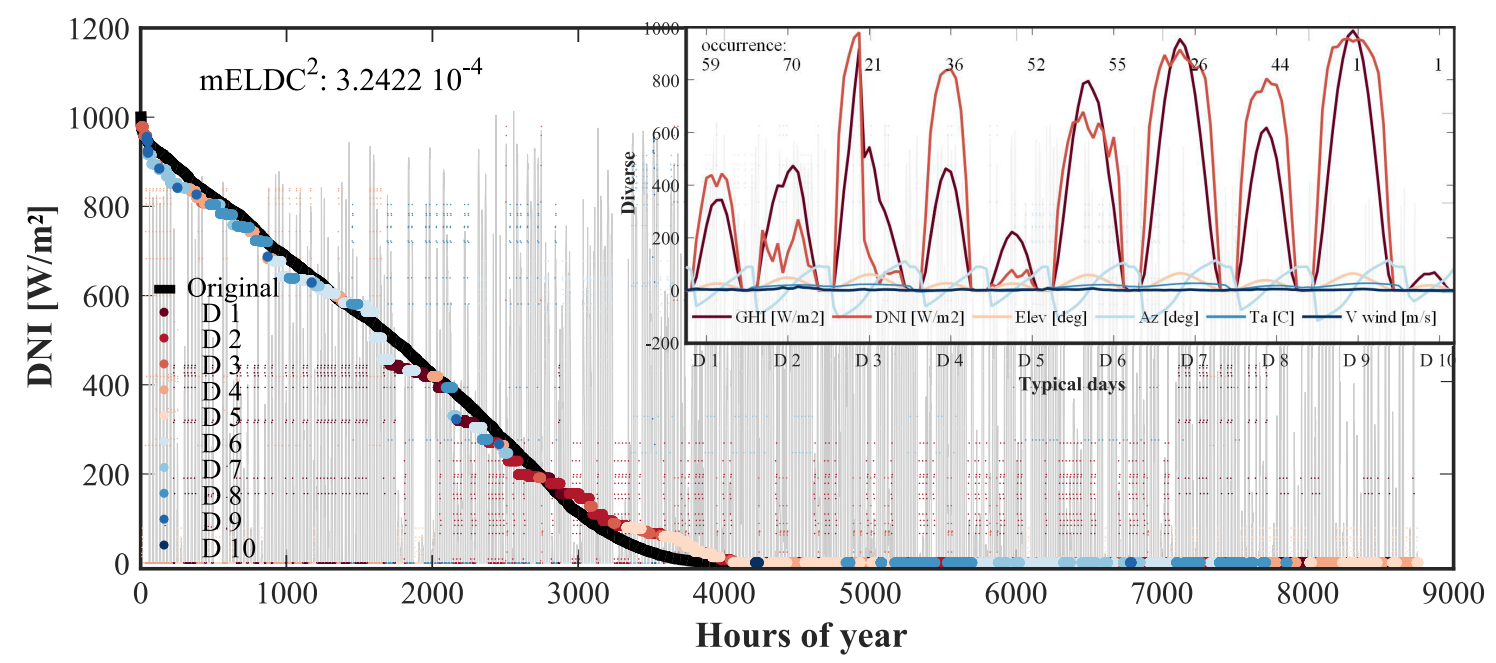

Figure 5: Load duration curve of DNI for Sion, Switzerland, of original data and 8 typical plus 2 extreme days. In background yearly distribution of DNI of original and typical days.

Data clustering. $k$-means or $k$-medoids clustering is usually applied when robustness to outliers is required, or when the mean or median do not have a clear meaning. Weather data for optimal design of solar systems naturally falls into both categories. $k$-medoids clustering was selected since the resulting set is always a subset of the original data. A MATLAB [37] function, which is based on the widely employed Partitioning Around Medoids (PAM) algorithm [27, was used in order to reduce the problem size from 8760 points of hourly weather data to below 500 points. In Appendix D the data and parameters are described in more detail. Following the indications of Dominguez et al. [20], the typical days were built from n clusters with 2 extreme days. For clustering, 3 indicators were chosen which influence the solar performance the most: DNI, GHI, and the ambient temperature. Since the DNI fluctuates the most on an hourly, daily, and monthly basis with a high influence on the solar output, it was chosen as the main reference for determination of the performance indicator. Also the extreme days were determined based on the DNI.

The procedure for finding the optimal number of clusters is divided into three steps:

1. Data normalization: The data are scaled such that all values are represented between zero and one [0,1]. Additionally, they are sub-divided into 365 data knots, each containing 24 hours of data.

2. $k$-medoids clustering: Data clustering is performed, increasing the number of clusters after each iteration until the stopping criterion is met.

3. Stopping criterion: The mean squared error of the normalized Load Duration Curve (LDC) of the DNI is used as stopping criterion, as it is found that the LDC is best representing the data characteristics. The limit is set to $3.5 \times 10^{-4}$.

$$
\mathrm{mELDC}^{2}=\frac{\sum_{t=1}^{8760}\left(\mathrm{LDC}_{\text {original }}(t)-\mathrm{LDC}_{\text {typical days }}(t)\right)^{2}}{8760}
$$

Figure 5 presents the results from the clustering algorithm. The load duration curve of the DNI is displayed for the original data and the typical days. In the background, the hourly data is displayed showing that high values can also be reached during winter. This is particular for the DNI as it is not reduced by cosine losses in contrast to the GHI. The fit of the LDC is below the pre-defined limit of $3.5 \times 10^{-4}$ and is also visibly acceptable. In the upper right corner the resulting typical days and their occurrence are illustrated. The two extreme days are represented only once. It can be seen that there are few days with very low DNI. 


\subsection{System resolution (B)}

This section presents the optimization problem formulation and the respective constraints. The sets presented in Subsection 2.2.1 are specified in the present case study in the following manner. The set of utility technologies $\mathbf{W}$ refers to Section 2.1 $\quad \mathbf{W}=\{$ boiler (BOI), refrigeration (REF), mechanical vapor re-compression (MVR), heat pump superstructure (HPS), flat plate solar (FP), photovoltaic modules (PV), concentrated photovoltaic and thermal system HCPVT), thermal storage (STO), cooling water (CW), electricity grid (GRID)\}. The set of periods $\mathbf{P}$ stems from Section 2.1.2.

\subsubsection{MILP utility targeting formulation}

The problem is formulated as a multi-period MILP that solves the heat cascade and finds optimal utility integration 8 10, 19. The general optimization problem is described by the following set of linear constraints. Scalar decision variables are represented by italic letters and parameters by standard text; vectors and sets are represented in bold.

Objective function. The problem objective is the minimization of the total annualized cost (TAC, depicted in Equation (1) which is composed of the operating cost of each utility technology $w$ during period $p$ and the annualized investment that is found with aid of the maximum size of each technology.

$$
\min _{y_{p}^{w}, f_{p}^{w}, y^{w}, f^{w}} \underbrace{\sum_{p=1}^{\mathbf{P}}\left(\sum_{w=1}^{\mathbf{W}} \mathrm{OP}_{1, p}^{w} \cdot y_{p}^{w}+\mathrm{OP}_{2, p}^{w} \cdot f_{p}^{w}\right) \cdot \Delta \mathrm{t}_{p} \cdot \mathrm{occ}_{p}}_{\text {Operating cost }}+\tau \cdot \underbrace{\sum_{w=1}^{\mathbf{W}} \mathrm{IV}_{1}^{w} \cdot y^{w}+\mathrm{IV}_{2}^{w} \cdot f^{w}}_{\text {Investment cost }}
$$

Where $\mathbf{P}$ is the set of periods $\left\{1,2,3, \ldots, \mathrm{N}_{p}\right\}, \mathbf{W}$ is the set of utility technologies , $f_{p}^{w} \in \mathbf{R}^{+}$is the multiplication factor of the reference size of a technology $w$ during period $p, y_{p}^{w}$ is a binary variable related to the existence of a technology $w$ during period $p, \mathrm{OP}_{1, p}^{w}[€ / \mathrm{h}]$ is the fixed operating cost for using the technology $w$ during period $p, \mathrm{OP}_{2, p}^{w}[€ / \mathrm{h}]$ is the proportional operating cost for using technology $w$ during period $p$ and is scaled with the multiplication factor, $\operatorname{IV}_{1}^{w}[€ / \mathrm{y}]$ is the fixed cost related to the investment of technology $w, \operatorname{IV}_{2}^{w}[€ / \mathrm{y}]$ is the proportional cost related to the investment of technology $w, \Delta \mathrm{t}_{p}[\mathrm{~h}]$ is the operating time of period $p, \operatorname{occ}_{p}[1 / \mathrm{y}]$ is the occurrence of period $p$, and $\tau=\frac{\mathrm{i} \cdot(1+\mathrm{i})^{\mathrm{n}}}{(1+\mathrm{i})^{\mathrm{n}}-1}[-]$ is the investment cost annualization factor.

Heat cascade constraints. The heat cascade constraints enforce the second law of thermodynamics, so that heat is only transferred from a hot temperature interval to a colder.

$$
\sum_{w=1}^{\mathbf{W}} f_{p}^{w} \cdot \mathrm{Q}_{p, j}^{w}+\sum_{s=1}^{\mathbf{S}} \mathrm{Q}_{p, j}^{s}+R_{p, j+1}-R_{p, j}=0 \quad \forall p \in \mathbf{P}, j \in \mathbf{J}
$$

Where, $\mathbf{J}$ is the set of temperature intervals $\left\{1,2,3, \ldots, \mathrm{N}_{j}\right\}, \mathbf{S}$ is the set of process streams, $\mathrm{Q}_{p, j}^{w}[\mathrm{~kW}]$ is the reference heat release or demand of a technology $w$ during period $p$ in the temperature interval $j, \mathrm{Q}_{p, j}^{s}$ $[\mathrm{kW}]$ is the heat release or demand of process stream $s$ during period $p$ in the temperature interval $j$, and $R_{p, j}[\mathrm{~kW}]$ is the residual heat of temperature interval $j$ that is cascaded to the next $j+1$ in period $p$.

Thermodynamic feasibility. The thermodynamic feasibility ensures a closed energy balance:

$$
R_{p, 1}=0, R_{p, \mathrm{~N}_{j}+1}=0, R_{p, i} \geq 0 \quad \forall i=\left\{1,2, \ldots, \mathrm{N}_{j}+1\right\}, p \in \mathbf{P}
$$

Existence of a technology. The maximum size of operation and existence of technology $w$ is given by:

$$
\begin{array}{lll}
f^{w}-f_{p}^{w} & \geq 0 & \forall w \in \mathbf{W}, p \in \mathbf{P} \\
y^{w}-y_{p}^{w} & \geq 0 & \forall w \in \mathbf{W}, p \in \mathbf{P} \\
\mathrm{f}^{w, \min } \cdot y_{p}^{w} \leq u_{p}^{w} \leq \mathrm{f}^{w, \max } \cdot y_{p}^{w} & \forall w \in \mathbf{W}, p \in \mathbf{P}
\end{array}
$$


Solar equation. An additional equation for the solar utilities is introduced, since their utilization (multiplication factor) which is equivalent to the installed capacity of collectors or panels cannot vary over different time steps. This stems from the intention to always operate the solar field at full capacity rather than allowing active shading of parts of the collector field or defocussing the trackers if less capacity is needed. Therefore, the multiplication factor in period $p$ needs to be equal to the maximum multiplication factor. This implies that if the solar system is delivering more heat than the amount needed by the process, cooling water will be consumed to evacuate the surplus heat.

$$
f^{w s}-f_{p}^{w s}=0 \quad \forall w s \in \mathbf{W}_{\mathbf{s}} \subset \mathbf{W}, p \in \mathbf{P}
$$

Where $\mathbf{W}_{\mathbf{s}}$ is the set of solar utility technologies. The solar radiation input and therefore the output does change with time, but that is accounted for in the constant solar heat release $\mathrm{Q}_{p, r}^{w s}[\mathrm{~kW}]$ during period $p$ (see Appendix C).

Computational environment. The overall thermo-economic model is solved in Lua-based platform OSMOSE developed at École Polytechnique Fédérale de Lausanne in Switzerland [38, 39. In the Lua-based platform, the MILP problem is converted to AMPL mathematical programming language [40] and then solved by CPLEX [1].

\subsection{2. $\varepsilon$-constraint}

As mentioned, an $\varepsilon$-constraint was added to the MILP which constrains the $\mathrm{CO}_{2}$-equivalent emissions of the system. The total $\mathrm{CO}_{2}$-equivalent emissions depicted in Equation 6 are found by taking into account emissions from natural gas consumption and the electricity grid. Life cycle assessment of the associated technologies is not considered. The positive impact on the grid created by selling solar electricity was as well disregarded.

$$
C O_{2, \text { tot }}=\sum_{p=1}^{\mathbf{P}}\left(\mathrm{CO}_{2, \mathrm{el}} \cdot \mathrm{E}^{\mathrm{GRID}} \cdot f_{p}^{\mathrm{GRID}, \mathrm{in}}+\mathrm{CO}_{2, \mathrm{ng}} \cdot \mathrm{Q}^{\mathrm{ng}} \cdot f_{p}^{\mathrm{BOI}}\right) \cdot \Delta \mathrm{t}_{p} \cdot \mathrm{occ}_{p}
$$

Where $\mathrm{CO}_{2, \mathrm{el}}\left[\mathrm{kgCO}_{2} \mathrm{eq} / \mathrm{kWh}\right]$ are the life cycle emissions related to buying electricity from the Swiss grid and $\mathrm{CO}_{2, \mathrm{ng}}\left[\mathrm{kgCO}_{2} \mathrm{eq} / \mathrm{kWh}\right]$ are the life cycle emissions from natural gas burning, $\mathrm{E}^{\mathrm{GRID}}[\mathrm{kW}]$ is the reference

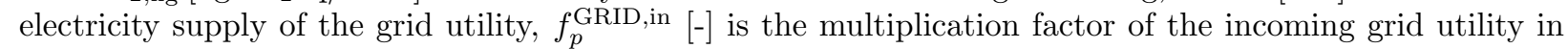
period $p, f_{p}^{\mathrm{BOI}}[-]$ is the multiplication factor of the boiler in period $p$, and $\mathrm{Q}^{\mathrm{ng}}[\mathrm{kW}]$ is the reference natural gas consumption in the boiler.

The $\varepsilon$-constraint ensures that the total emissions do not exceed $\varepsilon$, which is specified as a fraction of the reference emissions and which is incrementally changed in this work (between 95 and $60 \%$ of the reference emissions).

$$
C O_{2, t o t} \leq \varepsilon
$$

\subsection{Performance calculation $(C)$}

After the optimization step the non-linear functions, such as the investment cost are recalculated as well as other performance indicators depicted below. The necessary parameters are presented in Table 1 .

Operating cost. During the MILP optimization step, the buying price of electricity is set to the market price displayed in Table 1. while the selling price is set to a very small negative number. This serves as a protection against oversizing the photovoltaic systems not to become pure electricity exporters due to too high profits from selling electricity. The solar utilities are sized with the $\varepsilon$-constraint on the emissions.

In the Performance calculation step, the operating cost are recalculated with adequate numbers. It is assumed that the solar utilities do not have operating costs. Therefore, the total operating costs are composed of the electricity bought from or sold to the grid and the natural gas consumption in the boiler. 
Table 1: Data related to emissions, primary energy consumption and operating cost in Switzerland.

\begin{tabular}{llll}
\hline Parameter & Unit & Value & Source \\
\hline Ambient temperature $\mathrm{T}_{\mathrm{a}}$ & {$[\mathrm{K}]$} & 298 & {$[-]$} \\
Interest rate $\mathrm{i}$ & {$[-]$} & 0.05 & {$[-]$} \\
Equipment lifetime $\mathrm{n}$ & {$[$ years $]$} & 20 & {$[-]$} \\
Maintenance cost fraction of total investment & $\mathrm{m}$ & 0.05 & {$[-]$} \\
Cost of buying electricity op el,in & {$[€ / \mathrm{kWh}]$} & 0.142 & {$[42]$} \\
Cost of buying natural gas op & {$[€ / \mathrm{kWh}]$} & 0.081 & {$[42]$} \\
Emissions electricity $\mathrm{CO}_{2, \mathrm{el}}$ & {$\left[\mathrm{kgCO} \mathrm{CO}_{2} \mathrm{eq} / \mathrm{kWh}\right]$} & 0.11257 & {$[43]$} \\
Emissions natural gas $\mathrm{CO}_{2, \mathrm{ng}}$ & {$\left[\mathrm{kgCO}_{2} \mathrm{eq} / \mathrm{kWh}\right]$} & 0.20196 & {$[43]$}
\end{tabular}

The selling price of electricity is set to $80 \%$ of the buying price to represent the market situation more realistically.

$$
O P_{\mathrm{tot}}=\sum_{p=1}^{\mathbf{P}}\left(\mathrm{op}_{\mathrm{el}, \mathrm{in}} \cdot \mathrm{E}^{\mathrm{GRID}} \cdot\left(f_{p}^{\mathrm{GRID}, \text { in }}-0.8 \cdot f_{p}^{\mathrm{GRID}, \mathrm{out}}\right)+\mathrm{op}_{\mathrm{ng}} \cdot \mathrm{Q}^{\mathrm{ng}} \cdot f_{p}^{\mathrm{BOI}}\right) \cdot \Delta \mathrm{t}_{p} \cdot \mathrm{occ}_{p}
$$

Where op $\mathrm{ol}_{\text {el,in }}[€ / \mathrm{kWh}]$ is the electricity cost, $f_{p}^{\text {GRID,in }}[-]$ is the multiplication factor of the incoming grid utility in period $p, f_{p}^{\mathrm{GRID}, \text { out }}[-]$ is the multiplication factor of the outgoing grid utility in period $p$, The natural gas and electricity prices are depicted in Table 1 .

Investment cost. The investment cost of the units in-place (the boiler and standard refrigeration cycle) are not considered. Other investment cost functions can be found in Appendix B All cost data are actualized with the Marshall and Swift index [44. The total investment cost $I N V_{\text {tot }}$ is calculated as a sum of the maximum sizes of each utility technology $w$ in all periods $p$.

Total annual cost. The total annual cost is derived from the yearly operating cost $O P_{\text {tot }}$, the annualized investment, where $\tau$ is the annualization factor, and the maintenance cost, which is a fraction $\mathrm{m} \mathrm{[-]}$ of the total investment, see also Table 1 .

$$
T A C=O P_{\text {tot }}+I N V_{\text {tot }} \cdot(\tau+\mathrm{m})
$$

Carnot factor. The Carnot factor permits re-scaling the temperature levels on the standard composite curve. This has two advantages: firstly, the representation is more compact since the y-axis will always be in between -1 and 1 (equivalent to a temperature range of $[-124, \infty){ }^{\circ} \mathrm{C}$ ) which makes visualization of the process easier; and secondly, the factor is proportional to the exergetic potential of a temperature level and therefore exergetic losses between sources and sinks can be visualized.

$$
\eta_{\text {Carnot }}=1-\frac{\mathrm{T}_{\mathrm{a}}}{T}
$$

\section{Results and discussion}

\subsection{Scenario definition}

A set of cases is analyzed in order to gain a proper understanding of the different options for energy efficiency improvement and emissions reduction of the studied dairy plant. In Table 2, all possible utility technologies and investigated cases are presented.

The Original case refers to the current energy consumption of the plant without process integration (no maximum heat recovery) based on the utilities in place (boiler, one-stage ammonia based refrigeration cycle, and cooling water); the Reference case is based on the Original case, however, considering process integration with maximum heat recuperation. Subsequently, mechanical vapor re-compression around the process pinch (1. MVR) and a heat pump superstructure (2. HPS) improving the refrigeration cycle are proposed. The heat pump (1. MVR) was also proposed by Becker et al. [18. The subsequent cases including different solar scenarios and the heat pump superstructure display an extension to the previous analysis. 
Table 2: Investigated utility technology cases, first four cases: non-renewable utilities, next four: solar utilities. The grid (GRID) and cooling water (CW, Appendix B.1) utility technologies are present for all cases. The detailed models can be found in: Appendix B.2 (BOI), Appendix B.3 (REF, VCR\& HPS), Appendix C.1 (FP), Appendix C.3 (HCPVT), Appendix C.2 $(\mathrm{PV})$.

\begin{tabular}{|c|c|c|c|c|c|c|c|c|}
\hline Case & $\begin{array}{l}\text { Process } \\
\text { integr. } \\
(\mathrm{EI})\end{array}$ & $\begin{array}{l}\text { Boiler } \\
\text { (BOI) }\end{array}$ & $\begin{array}{l}\text { Ref- } \\
\text { rigeration } \\
(\mathrm{REF})\end{array}$ & $\begin{array}{l}\text { Vapor } \\
\text { re-comp. } \\
(\mathrm{MVR})\end{array}$ & $\begin{array}{c}\text { Heat pump } \\
\text { superstructure } \\
\text { (HPS) }\end{array}$ & $\begin{array}{c}\text { Solar } \\
\text { flat plate } \\
(\mathrm{FP})\end{array}$ & $\begin{array}{c}\text { Solar } \\
\text { HCPVT } \\
\text { (HCPVT) }\end{array}$ & $\begin{array}{c}\text { Solar } \\
\text { PV } \\
(\mathrm{PV})\end{array}$ \\
\hline Original & - & $\mathrm{X}$ & $\mathrm{X}$ & - & - & - & - & - \\
\hline Reference & $\mathrm{X}$ & $\mathrm{X}$ & $\mathrm{X}$ & - & - & - & - & - \\
\hline 1. MVR & $\mathrm{X}$ & $\mathrm{X}$ & $\mathrm{X}$ & $\mathrm{X}$ & - & - & - & - \\
\hline 2. HPS & $\mathrm{X}$ & $\mathrm{X}$ & $\mathrm{X}$ & $\mathrm{X}$ & $\mathrm{X}$ & - & - & - \\
\hline 2.1. FP & $\mathrm{X}$ & $\mathrm{X}$ & $\mathrm{X}$ & $\mathrm{X}$ & $\mathrm{X}$ & $\mathrm{X}$ & - & - \\
\hline 2.2. $\mathrm{PV}$ & $\mathrm{X}$ & $\mathrm{X}$ & $\mathrm{X}$ & $\mathrm{X}$ & $\mathrm{X}$ & - & - & $\mathrm{X}$ \\
\hline 2.3. PV\&FP & $\mathrm{X}$ & $\mathrm{X}$ & $\mathrm{X}$ & $\mathrm{X}$ & $\mathrm{X}$ & $\mathrm{X}$ & - & $\mathrm{X}$ \\
\hline 2.4. HCPVT & $\mathrm{X}$ & $\mathrm{X}$ & $\mathrm{X}$ & $\mathrm{X}$ & $\mathrm{X}$ & - & $\mathrm{X}$ & - \\
\hline
\end{tabular}

\subsection{Daytime operation of the process $(\Delta)$}

Throughout this Section, daytime only operation is investigated. Due to fewer operating hours and with that lower operating costs less space for investment decisions is left.

\subsubsection{Reference scenario and heat pump integration}

In this Subsection, the Reference case and efficiency improvements related to heat pump integration are in investigated. Therefore, mechanical vapor re-compression (1. MVR), and a multi-stage heat pump superstructure (2. HPS) are subsequently added to the Reference case which consists of the process demands considering heat recovery and the utilities in place (as described in Section 3.1).

Figure 6 depicts the integrated Carnot factor enthalpy profiles of the dairy process and respective three utility systems. The process curve is a rescaled version of the grand composite curve presented in Figure 3 and represents the net heating and cooling demands of the dairy process considering maximum heat recovery. The active utilities for each case, which are responsible for closing the energy balance, were selected and sized during the utility targeting step (in Section 2.2.1) by minimizing the total annual costs. The three investigated utility systems are depicted in this integrated Carnot factor enthalpy diagram as an envelope to the process composite curve (thus ensuring energy conservation). Figure 7 and Table 3 provide an illustration and the resulting data of the discussed scenarios, respectively.

Reference case. The utility envelope (black, Figure 6) of the Reference case shows at a high temperature plateau $\left(T \approx 1000^{\circ} \mathrm{C}, \eta_{\text {Carnot }}=0.77\right)$ the radiative heat release of the boiler $(\mathrm{BOI})$ and down to $50^{\circ} \mathrm{C}$ the convective heat release of its combustion gases. At $30^{\circ} \mathrm{C}\left(\eta_{\text {Carnot }}=0.02\right)$ the condensation level of the refrigeration system (REF) in place is visible. Cooling water $(\mathrm{CW})$ is consumed at $15^{\circ} \mathrm{C}\left(\eta_{\text {Carnot }}=-0.03\right)$ to remove the waste heat from the condensation of the refrigeration systems as well as part of the medium temperature waste heat from the process. The energy balance is closed with the evaporation level of the refrigeration cycle which provides refrigeration at $-2^{\circ} \mathrm{C}\left(\eta_{\text {Carnot }}=-0.1\right)$.

The exergy losses between the utility system and the process composite curve are represented by the area between the two curves. Especially between the boiler producing heat at very high temperatures, but also in the lower temperature range between the process self-sufficient pocket and the utility system drastic exergy losses are visible. This becomes increasingly clear when looking at the cooling water which is used for final cooling of the evaporation stage of the refrigeration cycle and partial cooling of the steam from the concentrated milk production which summed up to a cooling water consumption of $23.6 \mathrm{kWh} / \mathrm{t}$ of raw material (see Table 3).

The total annual costs, TAC, between the Original case and the Reference case were reduced from 5.9 to $4.3 € / \mathrm{t}$ of raw material if only the reduction in heating and cooling needs are considered and it reduced to $5.1 € / \mathrm{t}$ of raw material, if the estimated capital investment of the retrofit heat exchanger network (HEN) analysis are considered. 


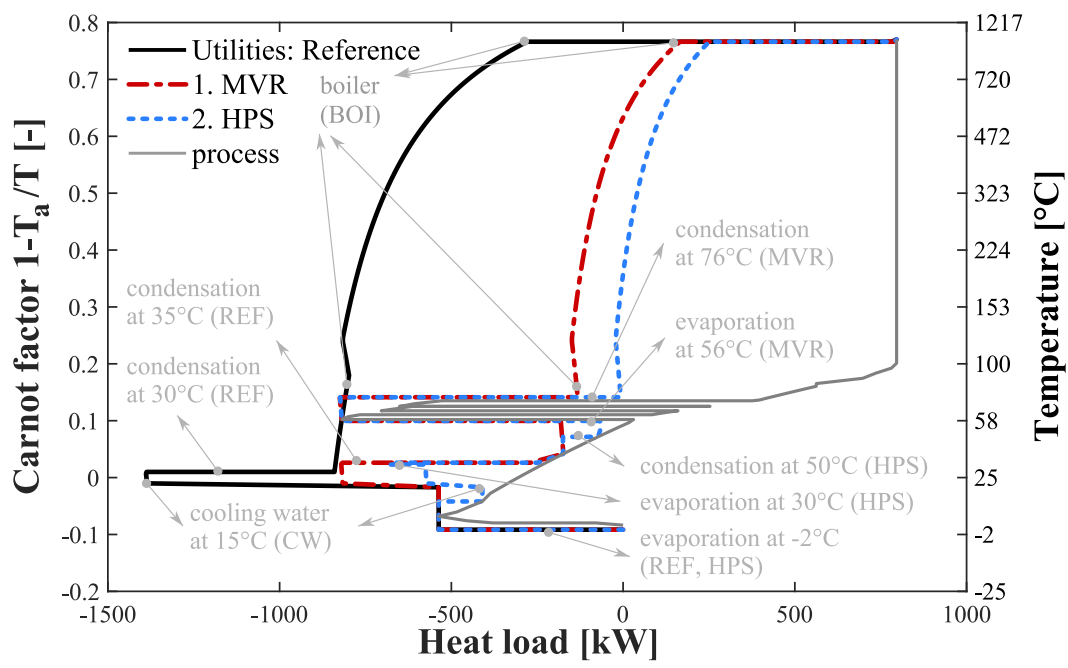

Figure 6: Integrated composite curves of the dairy process and respective utility system. [Reference] case with utilities in place, compared to case [1. MVR] with additional mechanical vapor re-compression around $67^{\circ} \mathrm{C}$, and [2. HPS] with additional heat pump superstructure between $-2,15,30$, and $50^{\circ} \mathrm{C}$.

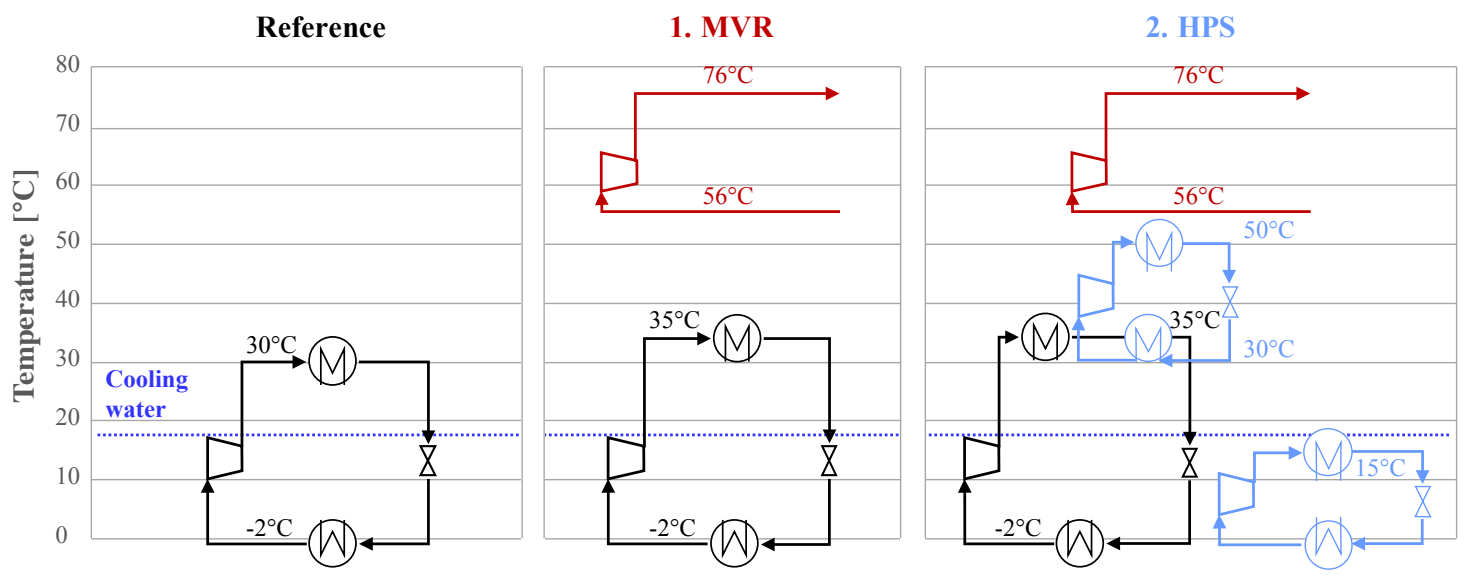

Figure 7: Illustration of the conversion cycles involved in the respective scenarios.

Table 3: Utility integration scenarios as described in Section 3.1 Costs and energy specific consumption data (referred to ton of raw material. $\left(^{*}\right)$ TAC neglecting HEN retrofit cost estimation

\begin{tabular}{|c|c|c|c|c|c|c|c|c|c|c|}
\hline & & & Original & Reference & 1. M & & 2. $\mathrm{H}$ & & & \\
\hline Operating costs & $\mathbf{O P}_{\text {tot }}$ & {$[€ / \mathrm{t}]$} & 5.9 & 4.3 & 2.9 & & 2.6 & & & \\
\hline Natural gas cons. & $\mathrm{Q}^{\mathrm{ng}}$ & {$[\mathrm{kWh} / \mathrm{t}]$} & 64.6 & 47.9 & 28.1 & & 24.3 & & & \\
\hline Electricity cons. & $\mathrm{E}^{\mathrm{GRID}}$ & {$[\mathrm{kWh} / \mathrm{t}]$} & 4.6 & 2.6 & 4.6 & & 4.8 & & & \\
\hline Compressor size & $\mathbf{E}^{\mathrm{HP}}$ comp & {$[\mathrm{kW}]$} & 167.0 & 94.7 & 111.8 & 55.2 & 87.5 & 65.1 & 10.4 & 9.7 \\
\hline Coeff. of performance & $\mathrm{COP}_{\mathrm{c}}$ & [-] & & 5.7 & 4.8 & 11.6 & 4.8 & 11.6 & 11.0 & 11.0 \\
\hline Cooling water cons. & $\mathrm{Q}^{\mathrm{cw}}$ & {$[\mathrm{kWh} / \mathrm{t}]$} & n.a. & 23.6 & 7.8 & & 4.5 & & & \\
\hline Compressor cap. exp. & INV $\mathrm{HP}_{\text {comp }}$ & {$[€ / t]$} & & 0 & 0 & 0.190 & 0 & 0.221 & 0.042 & 0.040 \\
\hline Heat exchang. area & $\mathbf{A}_{\text {tot }}^{\mathrm{HEN}}$ & {$\left[\mathrm{m}^{2}\right]$} & & 826 & 1032 & & 1161 & & & \\
\hline Number of HEX & $\mathbf{N}_{\min }^{\mathrm{HEN}}$ & {$[-]$} & & 48 & 64 & & 85 & & & \\
\hline HEN capital cost est. & INV $^{\text {HEN }}$ & {$[€ / \mathrm{t}]$} & & 0.9 & 1.2 & & 1.5 & & & \\
\hline TAC w/o HEN & TAC* & {$[€ / \mathrm{t}]$} & 5.9 & 4.3 & 3.1 & & 3.0 & & & \\
\hline Total annual costs & TAC & {$[€ / \mathrm{t}]$} & 5.9 & 5.1 & 4.3 & & 4.4 & & & \\
\hline
\end{tabular}


1. MVR. Introducing a mechanical vapor re-compression unit (1. MVR) elevates the pressure of the steam exiting the milk evaporation unit to produce useful heat above the process pinch. In Figure 66, this can be seen by two horizontal lines surrounding the process pinch $\left(\mathrm{T}=\{56,76\}^{\circ} \mathrm{C}, \eta_{\text {Carnot }}=\{0.1,0.15\}\right)$. What has to be noted is that by reusing the steam released in the milk production, the self-sufficient pocket is provided with less heat, meaning that the process can no longer be self-sufficient in the lower temperature range. This is, however, compensated by the evaporation stage of the refrigeration cycle which provides useful heat (at elevated condensation levels of $35^{\circ} \mathrm{C}$ ) to the process in this scenario. Exergetic losses were thus drastically diminished, as well as the cooling water (from 23.6 to $7.8 \mathrm{kWh} / \mathrm{t}$ of raw material, Table 3 and the natural gas consumption (from 47.9 to $28.1 \mathrm{kWh} / \mathrm{t}$ of raw material). The electricity usage was slightly increased (from 2.6 to $4.6 \mathrm{kWh} / \mathrm{t}$ of raw material) which permits the calculation of the incremental coefficient of performance $\mathrm{COP}=\Delta \mathrm{Q}^{\mathrm{ng}} / \Delta \mathrm{E}^{\mathrm{GRID}}=9.9[-]$. Where $\mathrm{Q}^{\mathrm{ng}}$ and $\mathrm{E}^{\mathrm{GRID}}$ are the natural gas and electricity consumption respectively (as reported in Table 3). On top of this improvement in efficiency, the total annual cost dropped from 5.1 in the Reference case to $4.3 € / \mathrm{t}$ of raw material due to drastic reductions in the operating costs.

The elevation of the condensation level (from 30 to $35{ }^{\circ} \mathrm{C}$ ) is an engineering choice which was motivated by the fact that the size of the mechanical vapor re-compression unit is constrained by how much heat could be delivered to the process from the evaporation stage of the refrigeration cycle. By elevating this temperature more use of vapor re-compression could be made and a higher incremental COP was be achieved. However, there is a limit to increasing the upper pressure of an existing compressor.

2. HPS. Therefore, a heat pump superstructure (2. HPS) is introduced to explore further installation of heat pumps with respect to the total annual costs. Adding the heat pump superstructure provides various options for single-and multi stage cycles between -2 and $50{ }^{\circ} \mathrm{C}$ (in $2{ }^{\circ} \mathrm{C}$ intervals) to the system resolution. With this, a new utility system configuration was found consisting of the refrigeration cycle in place, the mechanical vapor re-compression unit, and two new heat pump cycles between -2 and $15{ }^{\circ} \mathrm{C}$ and between 30 and $50{ }^{\circ} \mathrm{C}$. In Figure 6 it can be seen that this lead to a higher use of the mechanical vapor re-compression unit, because more heat could be provided to the process by the heat pumps. And this imposed a further decrease in the boiler consumption and, consequentially, a reduction of the exergy losses in the system. The total annual costs not considering the HEN costs (disregarded in the MILP) were reduced as well. However, considering the estimated capital expenses for the HEN, the TAC slightly increased from 4.3 to $4.4 € / \mathrm{t}$ of raw material. The cooling water consumption was further decreased from 7.8 to $4.5 \mathrm{kWh} / \mathrm{t}$ of raw material; and the electricity consumption was only slightly increased from 4.6 to $4.8 \mathrm{kWh} / \mathrm{t}$. This originated from the use of a lower temperature refrigeration cycle $\left(-2\right.$ to $\left.15{ }^{\circ} \mathrm{C}\right)$ with a higher $\mathrm{COP}_{\mathrm{c}}$ of 11 , which resulted in a reduction of the consumption of the refrigeration in place $\left(\mathrm{COP}_{\mathrm{c}} 4.8\right)$. Thereby the incremental COP was further improved to 24.2 [-] with respect to the previous scenario (1. MVR).

Summary. What can be concluded from here is that more complex systems (in terms of heat pumping) offer higher potential from the energetic point of view. And more complex systems require more complex tools (as illustrated with integration of the heat pump superstructure). However, there is always a trade-off between efficiency improvements accompanied by potential operating cost reduction and increase of the complexity of the system and therewith the heat exchanger network. The presented results indicate the strong potential of such installations and enunciates the importance of investigating selected case studies in further detail.

In the next Section, the relation between efficiency improvements (through heat pumping) on solar sizing is presented and general guidelines are provided.

\subsubsection{Heat pump \& solar integration}

Process schedule. Figure 8 depicts the process operating scheme and solar global horizontal (GHI) and direct normal (DNI) radiation during all typical periods. The winter days are marked by DNI levels exceeding the GHI, meaning that the sun elevation is not very high. The starting hours of the process operation was set to 8:00 o'clock in the morning lasting between 7 and 8 hours per day in order to form 2625 operating hours per year. This is a design choice attempting to overlap process operation with the sunshine hours. Observing the overlap between solar radiation and process operation, it becomes clear that there are several instances 


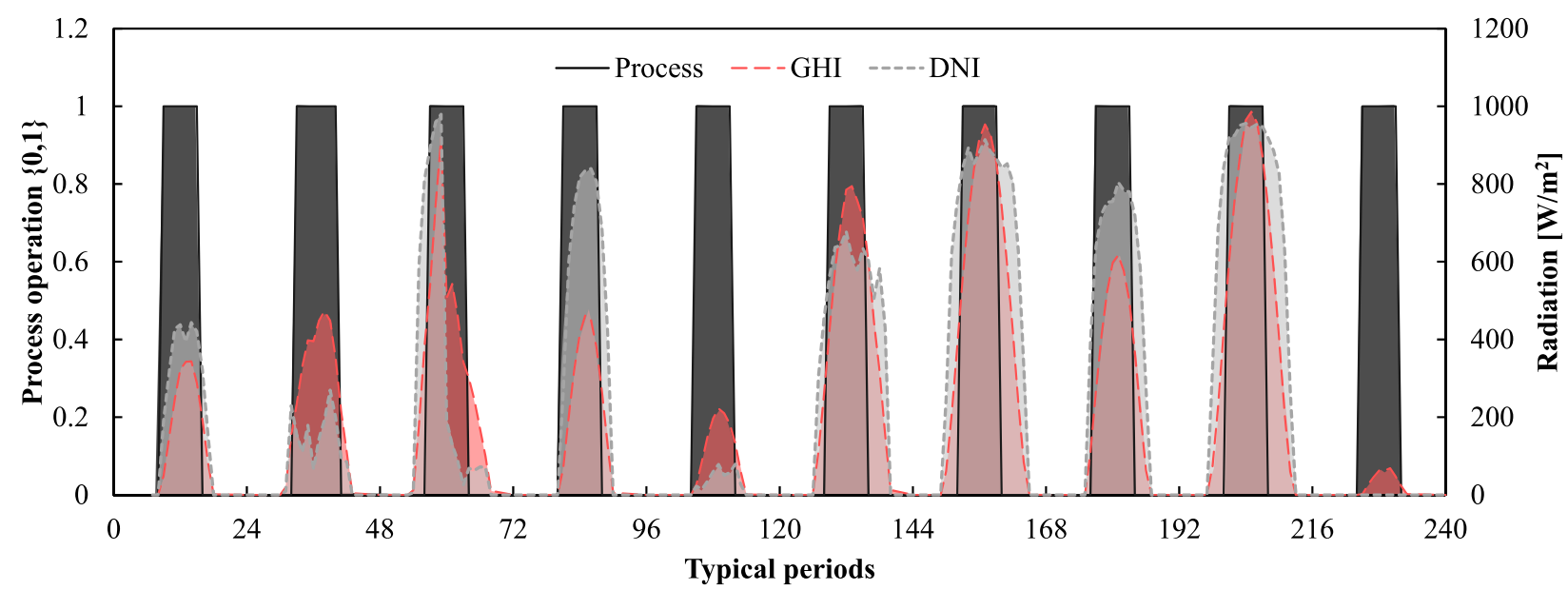

Figure 8: Process operation scheme and solar radiation during all typical periods. (GHI: Global Horizontal Irradiance, DNI: Direct Normal Irradiance.)

in which the overlap would be more aligned with the solar insolation if the process starting time was shifted to later in the morning. However. knowing that many manufacturing schedules traditionally start at earlier hours, 8:00 o'clock was the accepted trade-off.

In the daytime operation, the option of storage is not considered. As seen in Figure 8, the main lack of solar energy occurs in the early morning hours. It is difficult to store thermal energy over night and thus it was unreasonable to consider storage of solar energy for these periods of low solar productivity.

$\epsilon$-constraint optimization. The results from the $\varepsilon$-constraint optimization can be seen in Figure 9 . The two heat pump cases (1. MVR $6.2 \& 2$. HPS $5.5 \mathrm{~kg} \mathrm{CO}$-eq/t) were determined without $\varepsilon$-constraint as described in Section 3.2.1. Among these, the best scenario in terms of emissions was chosen as reference for the solar integration (2. HPS). For integration of the solar components the $\varepsilon$-constraint was gradually set to a fraction of these reference emissions (between 95 and 60\%) while minimizing the total system cost. In this way a Pareto type curve was produced (Figure 9(a)) between the annualized investment cost and the specific emissions. As expected, with decreasing emissions the annualized investment costs increased. The solar cases are presented with error bars (the data of which can be found in Appendix C.1Appendix C.2 Appendix C.3). Especially for the HCPVT system which is the most novel technology with the most volatile prices, this is a reasonable assumption. Under the current input data, the solar cases performed very similarly in terms of investment cost. The total annual cost in Figure 9(b) include besides the investment cost also the operating expenses. This leads to a different distribution of the data points. In terms of total annual cost, both heat pumping scenarios and most solar options were profitable with respect to the Reference case (of the utilities in place). The relative emission reductions amounted to $27 \%$ (between Original and Reference scenario) due to heat recuperation, $38 \%$ due to mechanical vapor re-compression (from Reference to 1 . MVR), and $12 \%$ due to improved refrigeration (from 1. MVR to 2. HPS). The solar scenarios further decreased the emissions by $5-40 \%(\varepsilon=95-60 \%)$ with respect to the 2 . HPS scenario.

It can be observed that some solar technologies potentially resulted in higher emission reductions than others. With PV modules the least reductions were achieved since they could not replace the boiler natural gas consumption; however, their advantage is the ability to sell overproduction to the grid. Still, up to $20 \%$ emission reduction was be achieved integrating solar PV. The reduction is achieved by replacing the incoming electricity from the grid with green electricity. The HCPVT system and combined FP and PV can reach the highest emission reductions at reasonable cost. At specific $\mathrm{CO}_{2}$ reductions of $3.8 \mathrm{~kg} \mathrm{CO}_{2}$ equivalent/ton of raw material, which is equivalent to $70 \%$ of the best heat pump only (reference) case, the TAC of all solar systems overlap, which indicates that this establishes an appropriate balance between operating, investment cost and energy waste. 
The uncertainty related to the solar investment cost is indicated on Figure 9, but not the uncertainty related to the heat exchanger area cost estimation. This is a rough estimation with errors varying between 20 and $40 \%$; therefore, grand conclusions should not be drawn when considering a difference in TAC between 10 and $20 \%$.

Figure 9(c) illustrates the associated total costs of the different scenarios. The operating cost are predominant in the Reference case, which explains the fact that the total cost of the solar scenarios did not drastically increase. This is attributed to a shift from operating expenses to specific investment cost.

A break even $\mathrm{CO}_{2}$ tax was calculated with respect to the case with lowest TAC (1. MVR). If the respective tax was applied all cases would exhibit the same costs as scenario 1. MVR. The tax lied between 100 and $300 €$ /ton $\mathrm{CO}_{2}$-equivalent which is slightly higher than the current prices, but in the same order of magnitude.

Figure 10(a) depicts the optimal active solar area for different $\mathrm{CO}_{2}$-equivalent emissions $(\varepsilon \in[60 \%, 95 \%])$ of all studied solar collector types. It can be observed that the required solar area increased with decreasing $\mathrm{CO}_{2}$-equivalent emissions. The relationship between emission reduction and active solar area does not follow a linear regression, but rather flattens out, especially for HCPVT and PV (and the lowest three FP data points) systems. This is attributed to the interconnectivity of the system, where higher solar thermal production has an influence also the utilization of the heat pumps and mechanical vapor re-compression and therewith on the electricity inflicted $\mathrm{CO}_{2}$-equivalent emissions. And vice versa, the solar electricity production directly affects the utilization of the heat pumps which influences the boiler consumption.

The HCPVT system required the smallest active area in comparison to the other solar technologies. This stems from the high total conversion efficiency. It has to be noted though that due to two axis tracking and
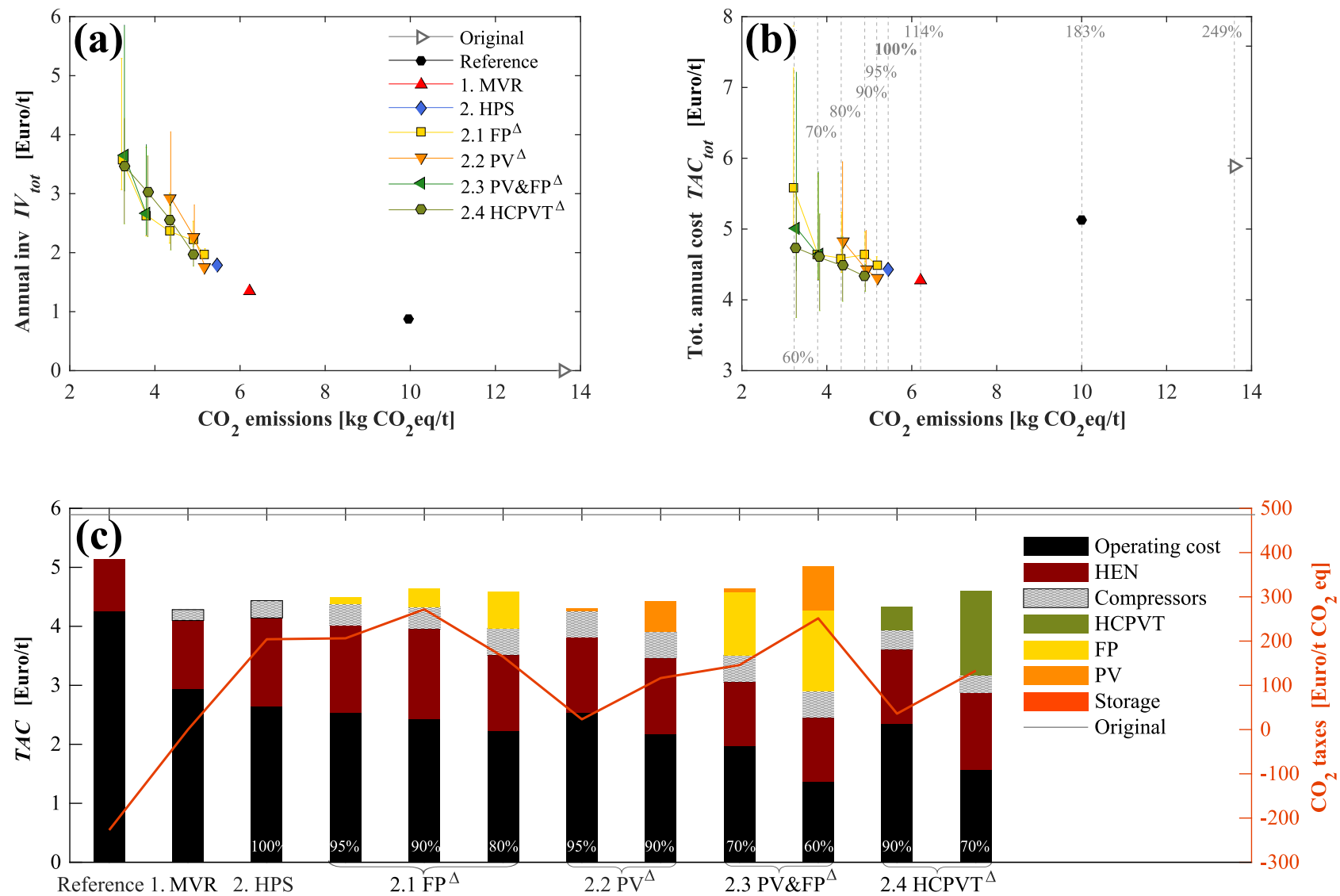

Figure 9: Results from $\varepsilon$-constraint optimization of different solar options for daytime only process operation. 
the danger of shading, the actual required land area may be increased by a factor of 2 .

Figure 10(b) shows the integrated Carnot factor enthalpy profiles of the dairy process and respective utility systems. Flat plate collectors (scenario $2.1 \mathrm{FP}$ ) at $80 \%$ emissions with respect to the 2 . HPS case (at $4.3 \mathrm{~kg} \mathrm{CO}$-equivalent/ton of raw material) are shown at solar noon during different typical days. The optimization results show that in comparison to the 2. HPS scenario, a different heat pump configuration was chosen: instead of two heat pumps $\left(30\right.$ to $50{ }^{\circ} \mathrm{C}$ and -2 to $15^{\circ} \mathrm{C}$ ) a two stage heat pump between -2 , 15 , and 50 with flash gas removal and intercooling at $30^{\circ} \mathrm{C}$ was selected during the MILP. In the curve, this can be traced with help of the missing evaporation plateau at $30^{\circ} \mathrm{C}$ which is present in case 2 .HPS. The higher operational cost due the higher electricity consumption were compensated by reduced natural gas consumption and apparently higher flexibility towards solar variations. This supports again the advantage of the holistic approach that takes into account the complete system for the complete operating range. It is further visible that the solar thermal production drastically contributed to reducing the exergetic losses between process and utility system, as it produces heat at temperatures much closer to the actual requirements.

Figure 11 shows a graphical representation of the multi-period results of case $2.1 \mathrm{FP}$ at $80 \%$ emissions with respect to case 2. HPS. In (a) the hot utility streams heat load and meteorological input data are shown, illustrating that the solar flat plate collector output (filled area) reduces the boiler consumption. The
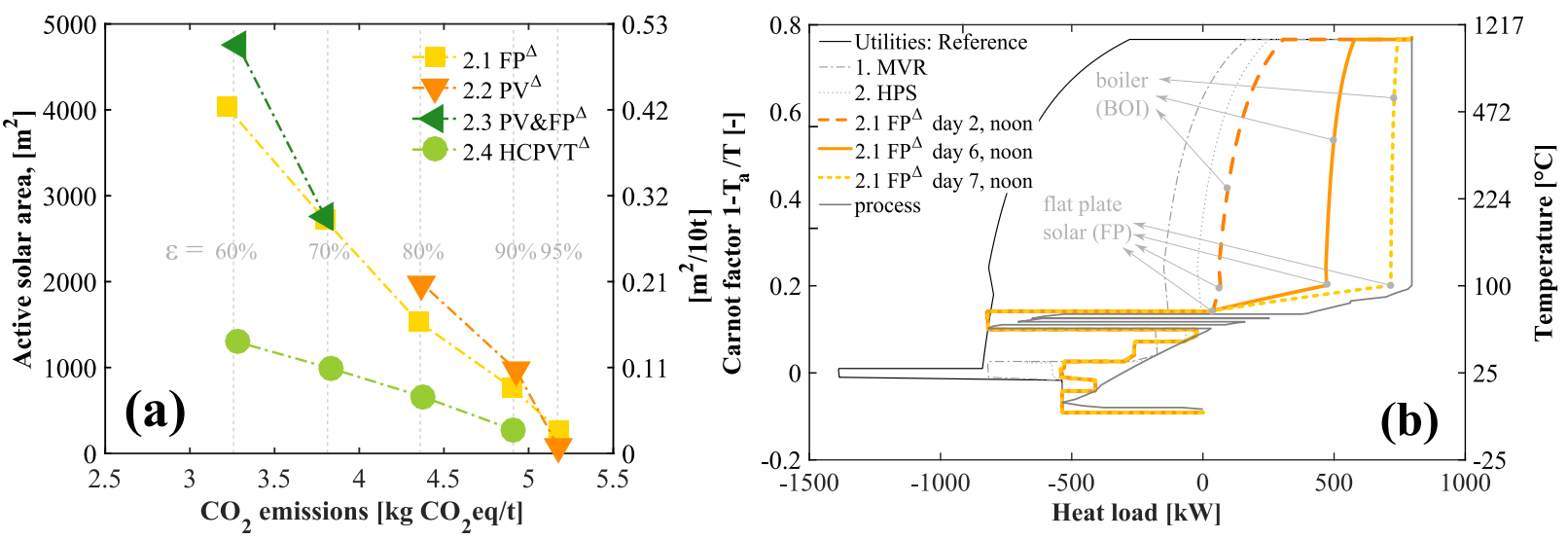

Figure 10: (a) Optimal active solar area, from $\varepsilon$-constraint optimization ( $\varepsilon$ between 95 and $60 \%$ ). (b) Integrated composite curves of the dairy process and respective utility system. [Reference, 1. MVR, 2. HPS] and Solar integration of Case 2.1 FP at $80 \%$ emissions with respect to the reference and $4.3 \mathrm{~kg} \mathrm{CO}_{2}$-equivalent/ton of raw material during different typical days.
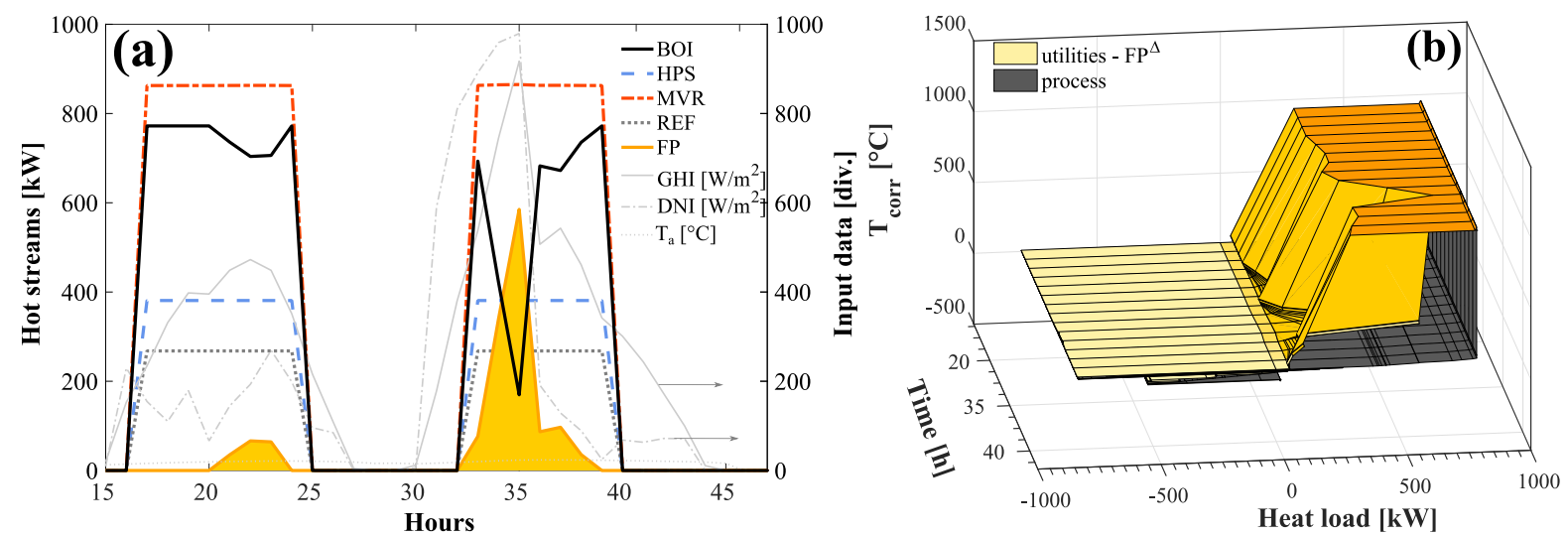

Figure 11: Solar integration, Case $2.1 \mathrm{FP}^{\Delta}$ at $80 \%$ emissions with respect to the reference i.e. $4.3 \mathrm{~kg} \mathrm{CO}_{2}$-equivalent/ton of raw material, multi-period MILP results: (a) hot utility streams heat load vs time, (b) multi-period integrated composite curves of the dairy process and respective utility system. 
solar output follows the available global radiation drawn in gray. In Figure 11(b) the respective integrated composite curves are shown for multiple periods. Close investigation shows the pattern of the solar output from Figure 11(a) in the high temperature plane of the boiler in the curves in Figure 11(b). This is related to the much lower operating temperatures of the solar system compared to the boiler and the related drop on the temperature axis.

It should be noted that the required boiler output changes drastically over time when solar heat is present. This might have an influence on the overall efficiency of the energy conversion if part load performance of the boiler is modeled in more detail, which was not considered here.

In conclusion, it can be stated that there is high economic and environmental potential for this type of industrial dairy plants for heat pump and solar integration. Results may be extrapolated to other low temperature food processing plants especially when operated in the underlying temperature range. Integration of both types of systems, solar and heat pumping should always be investigated with a holistic approach. For further steps, it is crucial to investigate the heat exchanger network design to explore technical feasibility of integrated systems.

\subsection{Continuous process operation $(O)$}

Throughout this Section, continuous process operation is investigated. Due to a higher number of operating hours (8760 vs $2625 \mathrm{~h}$ ) and with that increased operating costs more space for investment decisions is potentially available.

Figure 12 shows the results from the $\varepsilon$-constraint optimization. It can be observed that the raw material specific annualized investment cost were lower than the cost for the daytime only operation. This is explained by the higher operating hours and thus increased yearly raw material consumption. This increase had no
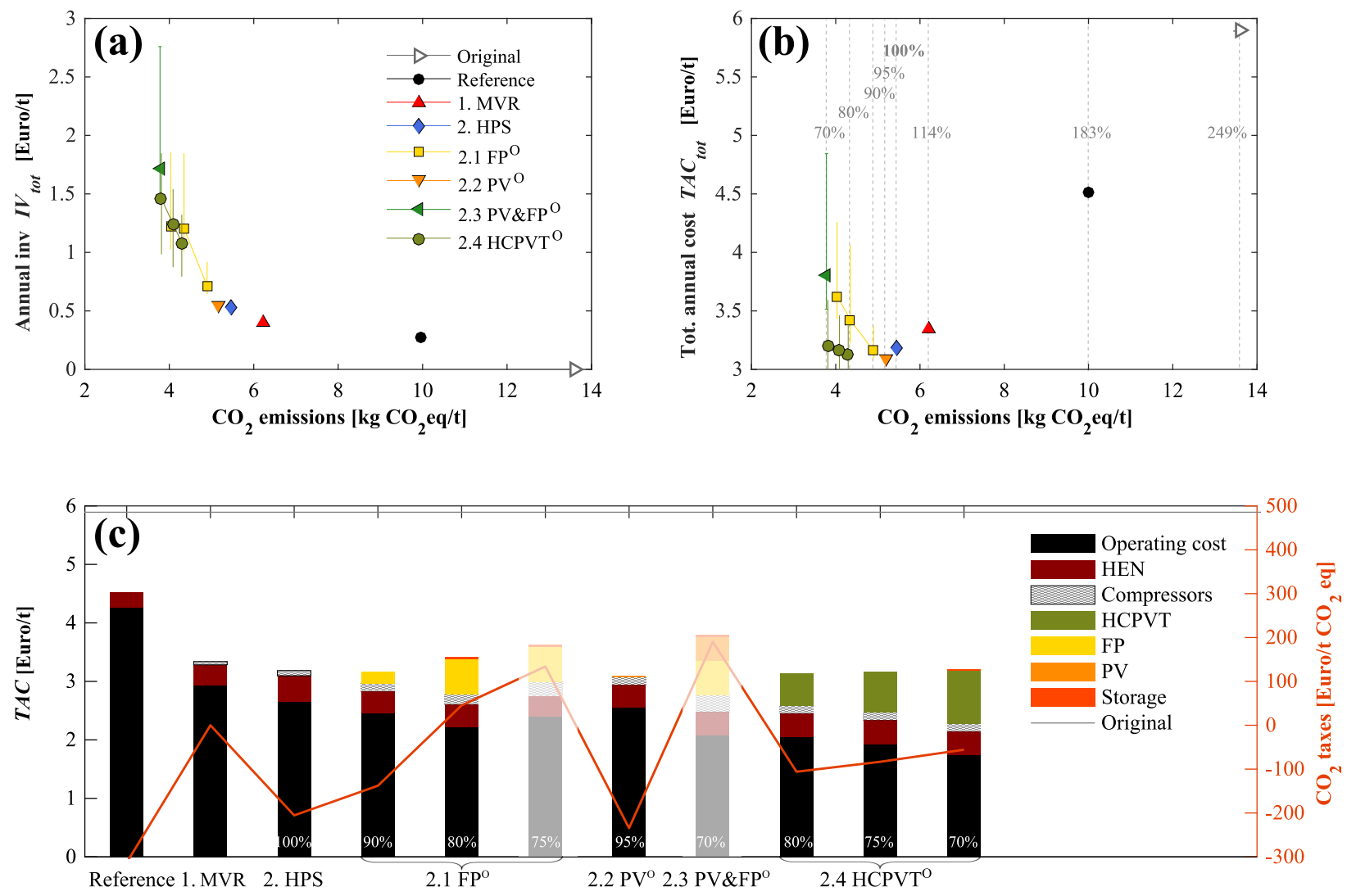

Figure 12: Results of $\varepsilon$-constraint optimization of different solar options for continuous process operation. 
influence on the specific operating cost which scale linearly with the raw material consumption. But the estimated HEN area and compressor sizes remains unchanged compared to daytime only operation and, therefore, the specific capital cost estimations decrease for a higher yearly raw material consumption. This leads to lower TAC of the 2. HPS scenario in comparison to 1 . MVR and daytime operation.

This decrease in relative specific investment costs also showed improvements for the flat plate (FP) and photovoltaic modules (PV) at low emission reductions $(\varepsilon=95 \%)$, which in this case are both profitable with respect to the best non-solar case (2. HPS). The PV system could not reach higher emission reductions than $95 \%$, because batteries are not considered and the positive impact from a renewable source to the grid is not counted. With increasing emission reductions the solar size and cost increased and the flat plate scenarios' TAC reached slightly above best non-solar case. The HCPVT exhibited the smallest specific TAC of all solar options as the overproduced electricity could be sold and therefore the operating costs decrease.

The option of storage was only chosen by the optimizer for emission reductions below and including $80 \%$ (FP) and $70 \%$ (HCPVT), respectively. This is attributed to the additional investment cost imposed by the storage. Therefore, if the emission goals could be achieved without storage, the storage was not selected. The storage volume of the FP cases amounted to $182 \mathrm{~m}^{3}(80 \%)$ which resulted in an investment cost of about $5 \%$ of the investment cost for the solar collectors, and for the HCPVT to $80 \mathrm{~m}^{3}(70 \%)$ which corresponded to $3 \%$ of the solar investment cost.

Figure 13(a) depicts the optimal active solar area for different $\mathrm{CO}_{2}$-equivalent emissions $(\varepsilon \in[70 \%, 95 \%])$ of all studied solar collector types. Similarly to the daytime only operation, it can be observed that the required solar area increased with decreasing $\mathrm{CO}_{2}$-equivalent emissions. This was, however, not the case between the FP 80 and $75 \%$ emission reductions. Referring to Figure 12 (c), it becomes clear that the improvement in emission reductions was achieved by an increase in operating cost and compressor investment cost, rather than an increase in solar collector area. This solution together with the $70 \% \mathrm{FP} \& \mathrm{PV}$ case should be excluded from further conclusions as they lead to an extreme oversizing of the heat pump system without thermodynamic needs in order fulfill the $\varepsilon$-constraint. This could be prevented by choosing more carefully the variable bounds for the heat pump cycles. As seen in the case of daytime only operation, it can be seen that the HCPVT system required the smallest active area in comparison to the other solar technologies for strong emission reductions due to high efficiency and high uptime.

Figure 13(b) shows the integrated composite curves of the dairy process and respective utility systems. The HCPVT system (scenario $2.1 \mathrm{HCPVT}$ ) at $70 \%$ emissions with respect to the 2 . HPS case (at $3.8 \mathrm{~kg}$ $\mathrm{CO}_{2}$-equivalent/ton of raw material) are shown at solar noon and evening during two typical days. The same heat pump configuration as for the daytime operation scheme was chosen by the optimizer: instead of two heat pumps $\left(30\right.$ to $50{ }^{\circ} \mathrm{C}$ and -2 to $15^{\circ} \mathrm{C}, 2$. HPS $)$ a two stage heat pump between $-2,15$, and 50 with
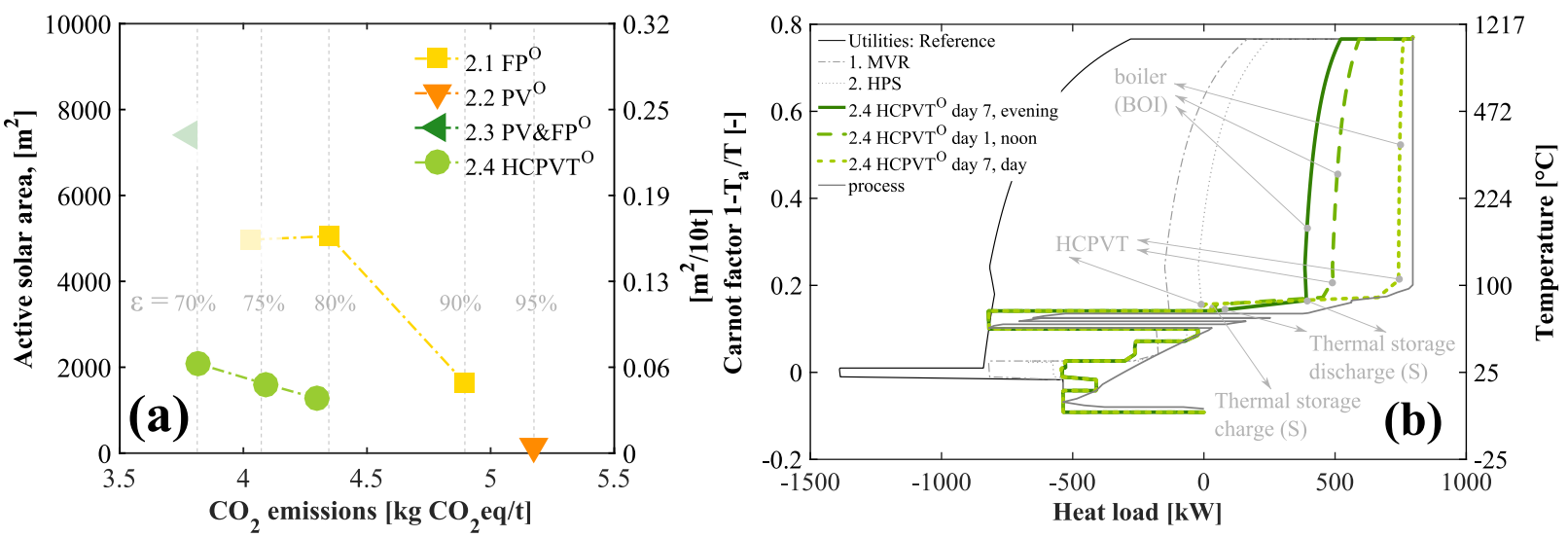

Figure 13: (a) Optimal active solar area, from $\varepsilon$-constraint optimization ( $\varepsilon$ between 95 and $70 \%$ ). (b) Integrated composite curves of the dairy process and respective utility system. [Reference, 1. MVR, 2. HPS] and Solar integration of Case 2.4 $\mathrm{HCPVT}^{\mathrm{O}}$ at $70 \%$ emissions with respect to the reference i.e. $3.8 \mathrm{~kg} \mathrm{CO}_{2}$-equivalent/ton of raw material during different typical days. 
flash gas removal and intercooling at $30^{\circ} \mathrm{C}$. During noon at day 1 , there was not enough solar heat available to cover the process demand completely which is why the boiler was required to back-up.

On day 7 at solar noon, the HCPVT produced heat which was not required by the process. As a result, the storage system was filled which can be seen by the little nose in the curve. This permits to store the surplus of heat in the thermal storage unit, which can then be released in the evening when solar heat is not available. This can be seen on the third curve, where the storage system provides the low temperature heat for the process and the HCPVT system is not active any more. The behavior of the storage system, boiler, and solar dish is further illustrated in Figure C.18 (in Appendix C.4) indicating a prolongation of the solar operation between $1-4$ hours (at $\varepsilon=70 \%$ ).

It has to be noted that with the HCPVT the boiler is always active to provide high temperature heat that cannot be provided by the HCPVT due to a process utility pinch. Limiting the operating range of the boiler between the maximum and a minimum at $80 \%$ of the maximum would make study of the storage system even more interesting and put aside the question of part load performance of the boiler, but was not considered in this work. This will, however, be subject to further studies.

\section{Conclusions}

The work presented here has proposed a comprehensive methodology that allows simultaneous optimization of the process' refrigeration and solar utility system with respect to economic and environmental criteria. This includes data collection and clustering, development of a heat pump superstructure, and multi-period, $\varepsilon$-constrained Mixed Integer Linear Programming (MILP) optimization. The proposed methodology was demonstrated on the basis of a dairy plant where different solar components are compared and evaluated based on the total cost and $\mathrm{CO}_{2}$-equivalent emissions. The methodology permits to derive cost optimal solar field, heat pump, and thermal storage tank sizing as well as optimal operation of the system during all operating periods at selected emission levels.

Optimization of heat recovery, heat pump, and mechanical vapor re-compression placement (disregarding the solar options) shows reduced exergy destruction and total costs at increased energy efficiency in the system.

Three solar systems were investigated for daytime only and continuous operation of the dairy process: photovoltaic modules (PV), flat plate collectors (FP), and a high concentration photovoltaic and thermal system (HCPVT). One mayor conclusion from the presented case study is that integration of solar energy can contribute to reduce the environmental impact and exergetic losses of the process at beneficial total costs. Solar energy is, however, only selected by the thermo-economic optimization algorithm in combination with an optimized system comprising heat recuperation, mechanical vapor re-compression, and heat pumping. This supports the choice of a comprehensive approach.

For continuous operation of the process, the reduction in specific emissions was not as significant as for daytime only operation. Due to the capital cost the thermal storage system, it is only chosen by the optimization for high emission reductions requirements. Photovoltaic panel integration offers the least emission reduction potential (up to $20 \%$ reduction in daytime only operation with respect to the best nonsolar case). However, installation is simple, independent, and if overproduced, can be exported to the grid. In comparison, the HCPVT system, has high potential with very high efficiencies bringing emission reductions easily up to $40 \%$ (daytime only) at uncertain cost and shading losses. The very low cost, low efficiency flat plate collectors offer a simple solution providing more reliability of the system performance capital cost expenses with emission reductions of up to $30 \%$ (daytime only).

\section{Acknowledgments}

The authors acknowledge the support of Swiss Federal Office of Energy SFOE (Grant SI/501487-01), SCCER EIP - Efficiency of Industrial Processes, and Airlight Energy SA for realizing this work. 


\section{References}

[1] Cedric Philibert. Solar Energy Perspectives. Technical report, International Energy Agency (IEA), 2011.

[2] Jose Antonio Quijera, Maria Gonzalez Alriols, and Jalel Labidi. Integration of a solar thermal system in a dairy process. Renewable Energy, 36(6):1843-1853, 2011.

[3] Christoph Lauterbach, S Javid Rad, Bastian Schmitt, and Klaus Vajen. Feasibility assessment of solar process heat applications. In Solar World Congress, Kassel, 2011.

[4] Soteris A. Kalogirou. The potential of solar industrial process heat applications. Applied Energy, 76(4):337-361, 2003.

[5] Bastian Schmitt, Christoph Lauterbach, and Klaus Vajen. Investigation of selected solar process heat applications regarding their technical requirements for system integration. In Proceedings ISES Solar World Congress Kassel, 2011.

[6] Mark R Shelton and Ignacio E Grossmann. Optimal synthesis of integrated refrigeration systems I: Mixed-integer programming model. Computers \& Chemical Engineering, 10(5):445-459, January 1986.

[7] Mark R Shelton and Ignacio E Grossmann. Optimal synthesis of integrated refrigeration systems II: Implicit enumeration scheme. Computers \& Chemical Engineering, 10(5):461-477, January 1986.

[8] Soterios A. Papoulias and Ignacio E. Grossmann. A structural optimization approach in process synthesis II. Computers \& Chemical Engineering, 7(6):707-721, January 1983.

[9] Soterios A. Papoulias and Ignacio E. Grossmann. A structural optimization approach in process synthesis I. Computers E6 Chemical Engineering, 7(6):695-706, January 1983.

[10] Soterios A. Papoulias and Ignacio E. Grossmann. A structural optimization approach in process synthesis III. Computers E Chemical Engineering, 7(6):723-734, January 1983.

[11] Shankar Vaidyaraman and Costas D. Maranas. Optimal synthesis of refrigeration cycles and selection of refrigerants. AIChE Journal, 45(5):997-1017, 1999.

[12] Konstantinos Holiastos and Vasilios Manousiouthakis. Minimum hot/cold/electric utility cost for heat exchange networks. Computers \& Chemical Engineering, 26(1):3-16, January 2002.

[13] F. Marchal and B. Kalitventzeff. A tool for optimal synthesis of industrial refrigeration systems. In Rafiqul Gani and Sten Bay Jorgensen, editor, Computer Aided Chemical Engineering, volume 9 of European Symposium on Computer Aided Process Engineering - 1134th European Symposium of the Working Party on Computer Aided Process Engineering, pages 457-462. Elsevier, 2001.

[14] Franois Marchal, Herve Closon, Boris Kalitventzeff, and Sauro Pierucci. A Tool for Optimal Synthesis of Industrial Refrigeration Systems: Application to an Olefins Plant. Technical report, 2002.

[15] Jian Zhang and Qiang Xu. Cascade refrigeration system synthesis based on exergy analysis. Computers E Chemical Engineering, 35(9):1901-1914, September 2011.

[16] Meysam Kamalinejad, Majid Amidpour, and S. M. Mousavi Naeynian. Thermodynamic design of a cascade refrigeration system of liquefied natural gas by applying mixed integer non-linear programming. Chinese Journal of Chemical Engineering, 23(6):998-1008, June 2015.

[17] Helen Becker, Francois Marechal, and Aurelie Vuillermoz. Process integration and opportunities for heat pumps in industrial processes. International Journal of Thermodynamics, 14(2):59-70, 2011.

[18] Helen Carla Becker. Methodology and Thermo-Economic Optimization for Integration of Industrial Heat Pumps. PhD thesis, 2012.

[19] Franois Marchal and Boris Kalitventzeff. Targeting the integration of multi-period utility systems for site scale process integration. Applied Thermal Engineering, 23(14):1763-1784, 2003.

[20] Fernando Dominguez-Munoz, Jose M Cejudo-Lopez, Antonio Carrillo-Andres, and Manuel Gallardo-Salazar. Selection of typical demand days for CHP optimization. Energy and buildings, 43(11):3036-3043, 2011.

[21] Samira Fazlollahi. Decomposition optimization strategy for the design and operation of district energy systems. PhD thesis, 2014.

[22] Martin J. Atkins, Michael R. W. Walmsley, and Andrew S. Morrison. Integration of solar thermal for improved energy efficiency in low-temperature-pinch industrial processes. Energy, 35(5):1867-1873, 2010.

[23] Simon Perry, Jiri Klemes, and Igor Bulatov. Integrating waste and renewable energy to reduce the carbon footprint of locally integrated energy sectors. Energy, 33(10):1489-1497, 2008.

[24] Hans Schnitzer, Christoph Brunner, and Gernot Gwehenberger. Minimizing greenhouse gas emissions through the application of solar thermal energy in industrial processes. Journal of Cleaner Production, 15(13-14):1271-1286, 2007.

[25] Samira Fazlollahi, Gwenaelle Becker, M. Guichard, and Francois Marechal. Multi-objective, multi-period optimization of district energy systems: Networks design, volume 32. June 2013.

[26] Anna S. Wallerand, Maziar Kermani, Ivan Kantor, Regis Voillat, and Francois Marechal. General Superstructure Synthesis and Bi-level Solution Strategy for Industrial Heat Pumping. In Submitted to Computer Aided Chemical Engineering, 27th European Symposium on Computer Aided Process Engineering. Elsevier, 2017.

[27] Leonard Kaufman and Peter J Rousseeuw. Finding groups in data: an introduction to cluster analysis, volume 344. John Wiley \& Sons, 2009.

[28] Lua.org. Lua 5.3 Reference Manual, https://www.lua.org/manual/5.3/. https://www.lua.org/manual/5.3/, Online; accessed 08-12-2016.

[29] Institut fur Solartechnik. Solar Prufung Forschung (SPF), Hochschule fur Technik Rapperswil. http://www.spf.ch/index.php?id=111\&no_cache=1, Online; accessed 11-02-2016.

[30] Keymark. THE Quality Label for Solar Thermal Products in Europe. The Solar Keymark. CEN Keymark Scheme, December 2016. Online; accessed 11-02-2016.

[31] SunTech. HyPro, STP 290s-20, Monocrystalline silicon. Accessed: 2016-01-14. 
[32] Airlight Energy Holding SA. www.airlightenergy.ch, Online; accessed: 2016-01-14.

[33] Angelos Selviaridis, Brian R. Burg, Anna S. Wallerand, Francois Marechal, and Bruno Michel. Thermo-economic analysis of a trigeneration HCPVT power plant. CPV conference Proceedings, 2015.

[34] Giv Zanganeh, Roman Bader, Andrea Pedretti, Marco Pedretti, and Aldo Steinfeld. A solar dish concentrator based on ellipsoidal polyester membrane facets. Solar Energy, 86(1):40-47, 2012.

[35] Max Schmitz, Gianluca Ambrosetti, and Aldo Steinfeld. Optical design of a multi-focus solar dish CPV system based on ellipsoidal mem-brane facets-Solar flux measurements. In 11 th SOLLAB Doctoral Colloquium, page 25.

[36] Meteonorm7.0. Irradiation data for every place on Earth. 2013

[37] MATLAB. version 8.6.0. (R2015b). The MathWorks Inc., Natick, Massachusetts, 2015.

[38] Raffaele Bolliger. Mthodologie de la synthse des systmes nergtiques industriels. 2010.

39] Min-Jung Yoo, Lindsay Lessard, Maziar Kermani, and Francois Marechal. OsmoseLua - An Integrated Approach to Energy Systems Integration with LCIA and GIS. In Kv Gernaey, Jk Huusom, and R Gani, editors, 12Th International Symposium On Process Systems Engineering (Pse) And 25Th European Symposium On Computer Aided Process Engineering (Escape), Pt A, volume 37 of Computer Aided Chemical Engineering, pages 587-592, Amsterdam, 2015. Elsevier Science Bv.

[40] Robert Fourer, David M. Gay, and Brian W. Kernighan. AMPL: A Modeling Language for Mathematical Programming. Duxbury Press / Brooks/Cole Publishing Company, 2003.

[41] IBM ILOG CPLEX Optimization Studio V12.7.0 documentation, February 2015

[42] International Energy Agency (IEA). Key World Energy Statistics 2015. Number 11.02.2016. February 2016. Online; accessed 11-02-2016.

[43] Rolf Frischknecht, Niels Jungbluth, Hans-Jrg Althaus, Gabor Doka, Roberto Dones, Thomas Heck, Stefanie Hellweg, Roland Hischier, Thomas Nemecek, Gerald Rebitzer, and others. The ecoinvent database: Overview and methodological framework (7 pp). The International Journal of Life Cycle Assessment, 10(1):3-9, 2005.

[44] Marshall and Swift. Marshall \& Swift Equipment Cost Index, 2017. http://www.equipment-costindex.com/eci/UserContentStart.aspx, Online; accessed 30-01-2017.

[45] Ian C. Kemp. Pinch Analysis and Process Integration: A User Guide on Process Integration for the Efficient Use of Energy. Butterworth-Heinemann, April 2011. Google-Books-ID: gQMxilJQmV4C.

[46] DW Townsend and B Linnhoff. Surface area targets for heat exchanger networks. In IChemE Annual Research Meeting, Bath, UK, 1984.

[47] B Linnhoff and S Ahmad. Cost optimum heat exchanger networks-1. Minimum energy and capital using simple models for capital cost. Computers \& Chemical Engineering, 14(7):729-750, 1990.

[48] Bodo Linnhoff, David R. Mason, and Ian Wardle. Understanding heat exchanger networks. Computers E\& Chemical Engineering, 3(14):295-302, 1979.

[49] Marcel Taal, Igor Bulatov, Jiri Klemes, and Petr Stehlik. Cost estimation and energy price forecasts for economic evaluation of retrofit projects. Applied Thermal Engineering, 23(14):1819-1835, 2003.

[50] S.G. Hall, S. Ahmad, and R. Smith. Capital cost targets for heat exchanger networks comprising mixed materials of construction, pressure ratings and exchanger types. 14(3):319-335, March 1990.

[51] Franois Marchal and Boris Kalitventzeff. Process integration: Selection of the optimal utility system. Computers \& Chemical Engineering, 22, Supplement 1:S149-S156, 1998.

[52] A Vuillermoz and G Guillotin. Intgration nergtique par analyse du pincement de la fromagerie bel evron: collecte des donnes, analyse e prconisations. Technical report, EDF Report H-E26-2010-01532-FR., 2011.

53] NREL. National Renewable Energy Laboratory. Renewable Resource Data Center. Number 11.02 .2016$. http://rredc.nrel.gov/solar/glossary/gloss_g.html, Online; accessed 11-02-2016.

[54] R. Perez, R. Stewart, C. Arbogast, R. Seals, and J. Scott. An anisotropic hourly diffuse radiation model for sloping surfaces: Description, performance validation, site dependency evaluation. Solar Energy, 36(6):481-497, 1986.

[55] Richard Perez, Robert Seals, Pierre Ineichen, Ronald Stewart, and David Menicucci. A new simplified version of the perez diffuse irradiance model for tilted surfaces. Solar Energy, 39(3):221-231, 1987.

[56] B.Y.H. Lui and R.C. Jordan. Daily insolation on surfaces tilted toward the equator. ASHRAE J., 3(10):53-59, 1961.

[57] John A Duffie and William A Beckman. Solar engineering of thermal processes, volume 4. Wiley New York etc., 2012.

[58] Pierre Ineichen, Olivier Guisan, and Richard Perez. Ground-reflected radiation and albedo. Solar Energy, 44(4):207-214, 1990.

[59] Paolo Ambrosetti, Johannes Keller, and Solar Heating. Das neue Bruttowrmeertragsmodell fr verglaste Sonnenkollektoren: Collaborative Programmes in energy $R, D \& D$, IEA: beeing part of the IEA Programme to develop and test solar heating and cooling systems; task III: Performance testing of solar collectors; subtask D: Characterization of the thermal performance of solar collectors. Eidgenssisches Institut fr Reaktorforschung, 1985.

[60] Tehnomont, Solarna Oprema Pula. SKT 100, Tested 2012. http://www.tehnomont-solari.hr/, Online; accessed: 2016-0114.

61] Solarstrom. go Solar GmbH | Solar Solarzellen Photovoltaik solarstrom. http://www.solarenergyshop.ch/index.php/de/20-Stueck-Photovoltaik-Modul-Suntech-Mono-BLACK-290-W-Total/c-KAT17/a-P0635, Online; accessed 24-01-2017.

[62] Stefano Moret, Emanuela Peduzzi, Leda Gerber, and Francois Marechal. Integration of deep geothermal energy and woody biomass conversion pathways in urban systems. Energy Conversion and Management, 129:305-318, 2016.

63] M. Gebhardt, H. Kohl, and T. Steinotter. PREISATLAS - Ableitung von Kostenfunktionen fur Komponenten der rationellen Energienutzung. Institut fr Energie-und Umwelttechnik e.V. (IUTA), 2002. 


\section{Appendix A. Heat Exchanger Network (HEN) cost}

The heat exchanger area is estimated as presented by Ian C. Kemp [45 47] (area targeting) based on vertical intervals placed between the hot and cold composite curves. In each interval the approximate heat exchanger area is estimated based on the logarithmic mean temperature difference, the hot and cold average heat transfer coefficients, and the heat transferred within the interval. The total area $A_{\text {tot }}^{H E N}\left[\mathrm{~m}^{2}\right]$ is found by the summing over all intervals. Estimation of the installed heat exchanger capital expenses springs from the assumption that all heat exchangers are equal.

$$
C_{p}^{H E N}=\mathrm{a}+\mathrm{b} *\left(\frac{A_{t o t, p}^{H E N}}{N_{\min , p}^{H E N}}\right)^{\mathrm{c}} * N_{\min , p}^{H E N}
$$

The minimum number of heat exchangers (units) $N_{\text {min }}^{\mathrm{HEN}}$ to be placed in each zone (between pinches) is estimated following the suggestion of Linnhoff et al. 48, based on graph theory. The cost correlations are taken from Taal et al. [49] reprinted from Hall et al. [50] and can be found in Table A.4 for retrofit heat exchanger costs. The total cost is calculated for each period $p \in \mathbf{P}$ and the final installed cost is then found as the maximum of all periods.

$$
C^{H E N}=\max _{p}\left(C_{p}^{H E N}\right)
$$

Table A.4: Heat exchanger network (HEN) cost estimation parameters from Hall et al. 50 reprinted by Taal et al. 49 (2.33) updated to $2015 €$, Carbon steel (CS)-CS heat exchangers.

\begin{tabular}{llll}
\hline Parameter & Symbol & Value & Unit \\
Heat exchanger cost estimations & HEN & & \\
\hline Fixed parameter & $\mathrm{a}$ & $9^{\prime} 500$ & $€$ \\
Scaling parameter & $\mathrm{b}$ & 460 & $€ / \mathrm{m}^{2}$ \\
Non-linear parameter & $\mathrm{c}$ & 0.8 & - \\
\hline
\end{tabular}

\section{Appendix B. Non-renewable technologies}

\section{Appendix B.1. Cooling water $(C W)$}

The cooling water is modeled by one cold stream between $15\left(\mathrm{~T}_{\mathrm{in}}^{\mathrm{cw}}\right)$ and $17^{\circ} \mathrm{C}\left(\mathrm{T}_{\mathrm{out}}^{\mathrm{cw}}\right)$. The operating cost are negligible as the cooling water is assumed to origin from a river close by the plant. The cooling thermal stream is formulated by the following relation, where $c_{p}^{C W}[\mathrm{~kJ} / \mathrm{kgK}]$ is the specific heat capacity, and $\mathrm{m}^{\mathrm{cw}}$, $1 \mathrm{~kg} / \mathrm{s}$, is the reference mass flow rate.

$$
\mathrm{Q}^{\mathrm{CW}}=\mathrm{m}^{\mathrm{CW}} \cdot \mathrm{c}_{\mathrm{p}}^{\mathrm{CW}} \cdot\left(\mathrm{T}_{\mathrm{out}}^{\mathrm{CW}}-\mathrm{T}_{\mathrm{in}}^{\mathrm{CW}}\right)
$$

\section{Appendix B.2. Boiler (BOI)}

The boiler heat release is modeled by three streams: air preheating, radiative and convective thermal power from natural gas combustion. The total heat release is derived by a multiplication of the lower heating value (LHV) with the reference fuel flow rate including the efficiency. Cooling down the combustion gases from the adiabatic flame temperature to a pre-defined radiation temperature defines the radiative component and is displayed as a hot stream at constant temperature (radiation temperature). The convective component is defined as a hot stream between the radiation temperature and the exhaust gases outlet temperature. The air preheating is written as a cold stream from ambient to preheating temperature. This practice has been published by Maréchal et al. 51 and is applied in the same manner by Becker et al. 18. The heat release is illustrated below in equation B.2 


$$
\mathrm{Q}^{\mathrm{BOI}}=-\left.\mathrm{Q}_{\text {pre }}\right|_{\mathrm{T}_{\mathrm{a}}} ^{\mathrm{T}_{\text {preh }}}+\left.\mathrm{Q}_{\text {rad }}\right|_{\mathrm{T}_{\mathrm{rad}}}+\left.\mathrm{Q}_{\text {conv }}\right|_{\mathrm{T}_{\text {out }}} ^{\mathrm{T}_{\mathrm{rad}}}
$$

The parameters are described in Table B.5. The boiler investment cost is set to zero, since it is already in-place. The natural gas consumption (eq. B.3) is derived from the boiler useful heat release based on a conversion fraction. The conversion fraction includes the thermal losses as well as the part of the heat released in the combustion that is dispensed in the exhaust gases and therefore not delivered to the process as useful heat.

$$
\mathrm{Q}^{\mathrm{ng}}=\mathrm{Q}^{\mathrm{BOI}} / \mathrm{f}^{\mathrm{BOI}}
$$

Table B.5: Boiler (BOI) parameters, adapted from 18.

\begin{tabular}{llll}
\hline Parameter & Symbol & Value & Unit \\
\hline Investment (in-place) & $\mathrm{IV}^{\mathrm{BOI}}$ & 0 & $€ / \mathrm{kW}$ \\
Adiabatic flame temperature & $\mathrm{T}_{\mathrm{ad}}^{\mathrm{f}}$ & 2768 & ${ }^{\circ} \mathrm{C}$ \\
Radiation temperature & $\mathrm{T}_{\mathrm{rad}}$ & 1027 & ${ }^{\circ} \mathrm{C}$ \\
Exhaust gases temperature & $\mathrm{T}_{\text {out }}$ & 120 & ${ }^{\circ} \mathrm{C}$ \\
Air preheating temperature & $\mathrm{T}_{\text {preh }}$ & 120 & ${ }^{\circ} \mathrm{C}$ \\
Radiative heat load & $\mathrm{Q}_{\text {rad }}$ & 28842 & $\mathrm{~kW}$ \\
Convective heat load & $\mathrm{Q}_{\text {conv }}$ & 15031 & $\mathrm{~kW}$ \\
Air preheating load & $\mathrm{Q}_{\text {preh }}$ & 1740 & $\mathrm{~kW}$ \\
Boiler conversion fraction & $\mathrm{f}^{\mathrm{BOI}}$ & 90 & $\%$ \\
\hline
\end{tabular}

\section{Appendix B.3. Heat pump superstructure}

In the following, the heat and electricity consumption and production of all heat pump utilities are described for a reference mass flow rate which is to say, a fixed size. These parameters enter into the utility targeting constraints (1)-(4) and are multiplied with sizing factors.

The heat release in a condenser at temperature level $T_{i}$ of fluid $f$ for a reference flow rate $\mathrm{m}_{\text {ref }}$ is composed of two parts: condensation at the saturation temperature and subcooling between saturation and subcooling temperature. Likewise, the heat consumption in an evaporator is defined.

$$
\begin{aligned}
\mathrm{Q}_{\mathrm{i}}^{\mathrm{HP}_{\text {cond/evap }}} & =\mathrm{m}_{\text {ref }} \cdot\left(\left[\mathrm{h}_{\mathrm{V}}\left(\mathrm{T}_{\mathrm{i}}\right)-\mathrm{h}_{\mathrm{L}}\left(\mathrm{T}_{\mathrm{i}}\right)\right]_{\mathrm{T}_{\mathrm{i}}}+\left[\mathrm{h}_{\mathrm{L}}\left(\mathrm{T}_{\mathrm{i}}\right)-\mathrm{h}_{\mathrm{SC}}\left(\mathrm{T}_{\mathrm{i}}\right)\right]_{\mathrm{T}_{\mathrm{i}, \mathrm{SC}}}^{\mathrm{T}_{\mathrm{i}}}\right) \\
& =\mathrm{m}_{\text {ref }} \cdot\left(\Delta \mathrm{h}_{\text {cond/evap }}\left(\mathrm{T}_{\mathrm{i}}\right)+\Delta \mathrm{h}_{\mathrm{SC}}\left(\mathrm{T}_{\mathrm{i}}\right)\right)
\end{aligned}
$$

Also the liquid side of the presaturator needs to be cooled down to the subcooling temperature.

$$
\mathrm{Q}_{\mathrm{i}}^{\mathrm{HP} \mathrm{p}_{\text {presat }, \mathrm{SC}}}=\mathrm{m}_{\text {ref }} \cdot\left[\mathrm{h}_{\mathrm{L}}\left(\mathrm{T}_{\mathrm{i}}\right)-\mathrm{h}_{\mathrm{SC}}\left(\mathrm{T}_{\mathrm{i}}\right)\right]_{\mathrm{T}_{\mathrm{i}, \mathrm{SC}}}^{\mathrm{T}_{\mathrm{i}}}
$$

Desuperheating from the superheated vapor balance can be achieved by mixing in the presaturator or with help of a heat exchanger.

$$
\mathrm{Q}_{\mathrm{i}}^{\mathrm{HP} \mathrm{Pesup}_{\mathrm{Q}}}=\mathrm{m}_{\text {ref }} \cdot\left[\mathrm{h}_{\mathrm{SH}}\left(\mathrm{T}_{\mathrm{i}}\right)-\mathrm{h}_{\mathrm{V}}\left(\mathrm{T}_{\mathrm{i}}\right)\right]_{\mathrm{T}_{\mathrm{i}}}^{\mathrm{T}_{\mathrm{i}, \mathrm{H}}}
$$

The power consumption depends on the isentropic efficiency and the enthalpies of both pressure levels.

$$
\mathrm{E}_{\mathrm{k} \rightarrow \mathrm{i}}^{\mathrm{HP} \text { comp }}=\mathrm{m}_{\text {ref }} \cdot\left[\frac{\mathrm{h}_{\text {isentropic }, \mathrm{k}}\left(\mathrm{T}_{\mathrm{i}}\right)-\mathrm{h}_{\mathrm{V}}\left(\mathrm{T}_{\mathrm{j}}\right)}{\eta_{\text {isentropic }}}\right]
$$

The non-linear cost function for compressors [in $€, 2010]$ is formulated after reference [52] reprinted by [18] where the installation factor was assumed to be 1.5.

$$
\mathrm{IV}^{\mathrm{HP}, \mathrm{comp}}=1.5 \cdot 1500 \cdot 160^{0.1} \cdot\left(\mathrm{E}_{\mathrm{HP}, \mathrm{comp}}\right)^{0.9}
$$


To ensure mass and energy conservation within the heat pump, linear constraints are defined at all liquid, vapor and superheated vapor points. These constraint are added to the utility targeting constraints. These equations are further documented in 26 .

Figure B.14 presents the annualized compressor capital costs as a function of the compressor power rating including the maintenance cost and its linear fitting function which was assumed during the MILP problem resolution.

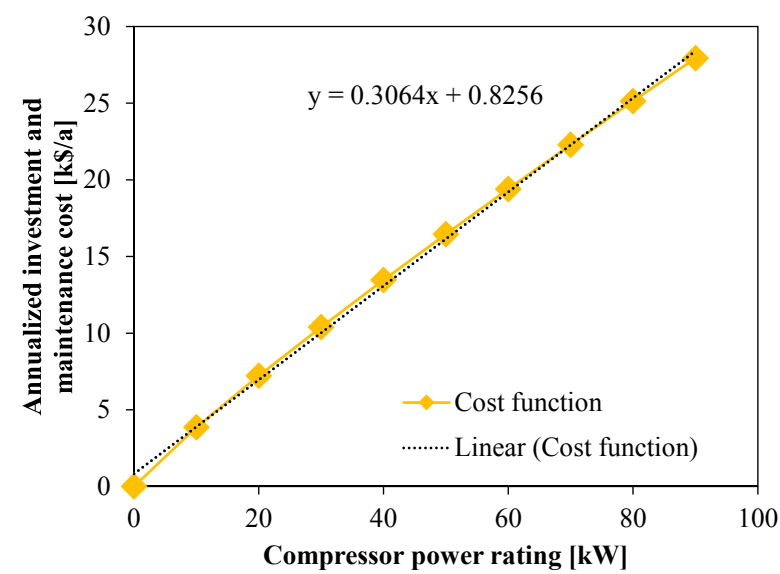

Figure B.14: Linearized, annualized capital cost function of the compressor, including maintenance costs.

Table B.6: Heat pump parameters.

\begin{tabular}{|c|c|c|c|}
\hline Parameter & Symbol & Value & Unit \\
\hline \multicolumn{4}{|l|}{ Heat pump superstructure (HPS) } \\
\hline Investment & $\mathrm{IV}^{\mathrm{HPs}}$ & eq. (B.8) & \\
\hline Temperatures & $\mathrm{T}_{\text {cond, } 1}^{\mathrm{HPS}}$ & $-2,10,15,20,25,30,35,40,45,50$ & ${ }^{\circ} \mathrm{C}$ \\
\hline Isentropic compressor efficiency & $\eta_{\text {comp }}^{\text {HPS }}$ & 0.76 & - \\
\hline Fluid & Ammonia & & \\
\hline \multicolumn{4}{|l|}{ Refrigeration in-place (REF) } \\
\hline Investment & $\mathrm{IV}^{\mathrm{REF}}$ & 0 & $€ / \mathrm{kW}$ \\
\hline Condenser temperature & $\mathrm{T}_{\text {cond }}^{\mathrm{REF}}$ & $30 \& 35$ & ${ }^{\circ} \mathrm{C}$ \\
\hline Evaporator temperature & $\mathrm{T}_{\text {evap }}^{\mathrm{REF}}$ & -2 & ${ }^{\circ} \mathrm{C}$ \\
\hline Isentropic compressor efficiency & $\eta_{\mathrm{comp}}^{\mathrm{REF}}$ & 0.76 & - \\
\hline Fluid & Ammonia & & \\
\hline \multicolumn{4}{|c|}{ Vapor recompression as proposed by [18] (MVR) } \\
\hline Investment & $\mathrm{IV}^{\mathrm{HP}}$ & eq. B.8) & \\
\hline Condenser temperature & $\mathrm{T}_{\text {cond }}^{\mathrm{HP}}$ & 76 & ${ }^{\circ} \mathrm{C}$ \\
\hline Evaporator temperature & $\mathrm{T}_{\text {evap }}^{\mathrm{HP}}$ & 56 & ${ }^{\circ} \mathrm{C}$ \\
\hline Isentropic compressor efficiency & $\eta_{\mathrm{comp}}^{\mathrm{HP}}$ & 0.76 & - \\
\hline Fluid & Water & & \\
\hline
\end{tabular}

\section{Appendix C. Solar technologies}

Global horizontal radiation. The global solar radiation incident on a plane is composed partly of direct and partly of diffuse radiation reflected from the ground, clouds and the atmosphere. A common measurement provided by weather stations around the globe is the Global Horizontal Radiation $\left(\mathrm{GHI}, \mathbf{g}_{\mathbf{h}},\left[\mathrm{W} / \mathrm{m}^{2}\right]\right.$ ) as 
well as the Direct Normal Incindence (DNI, $\mathbf{b}_{\mathbf{n}},\left[\mathrm{W} / \mathrm{m}^{2}\right]$ ) or beam radiation. The GHI is derived from the diffuse and the direct radiation incident on the plane $[53]$.

$$
\begin{aligned}
\mathbf{g}_{\mathbf{h}} & =\mathbf{d}_{\mathbf{h}}+\mathbf{b}_{\mathbf{h}} \\
& =\mathbf{d}_{\mathbf{h}}+\mathbf{b}_{\mathbf{h}} \cdot \cos \left(\boldsymbol{\theta}_{\mathbf{s}}\right)
\end{aligned}
$$

where $\mathbf{d}_{\mathbf{h}}\left[\mathrm{W} / \mathrm{m}^{2}\right]$ is the diffuse horizontal and $\mathbf{b}_{\mathbf{h}}\left[\mathrm{W} / \mathrm{m}^{2}\right]$ is the direct horizontal radiation, $\boldsymbol{\theta}_{\mathbf{s}}\left[^{\circ}\right]$ is the solar zenith angle indicated in Figure C.15 (in grey) as the angle between the earth surface normal (zenith) and the sun.

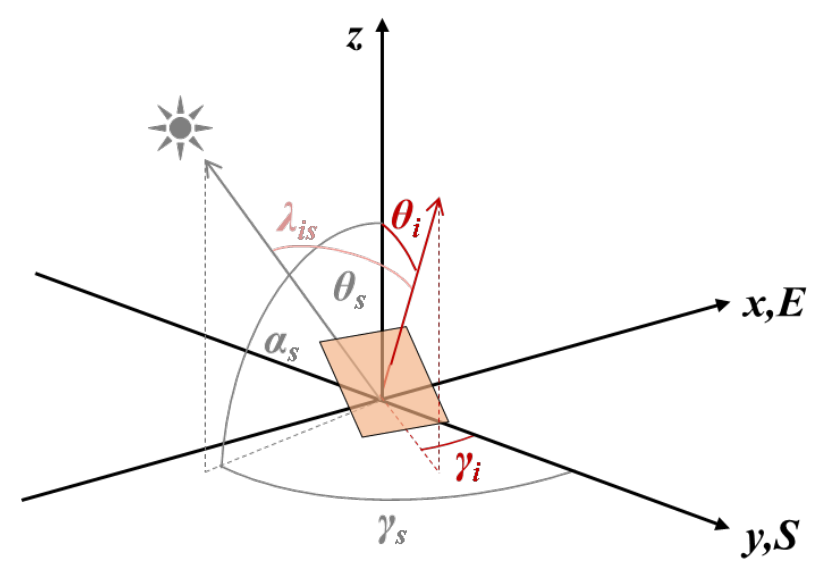

Figure C.15: Angles of the sun and an inclined surface.

Global radiation on inclined surface. The global radiation present on an inclined surface (i) is derived from the solar beam on the slope and the present diffuse radiation. The direct beam on an inclined surface is calculated by the product of the direct horizontal radiation and the cosine of the incidence angle between beam and slope. Calculation of the diffuse component on a slope is not trivial since the diffuse sky radiation is anisotropic meaning that it is not uniformly distributed over the hemisphere. Perez et al. 54, 55, offer correlations for modeling the anisotropic component of the diffuse radiation. In order to keep the problem at reasonable complexity the isotropic diffuse model proposed by Liu and Jordan [56, reprinted in [57. is used in this work. It is divided into three components: the beam, isotropic diffuse, and global radiation diffusely reflected from the ground (Eq. 2.15.1 [57]).

$$
\begin{aligned}
\mathbf{g}_{\mathbf{i}} & =\underbrace{\mathbf{b}_{\mathbf{n}} \cdot \cos \left(\boldsymbol{\lambda}_{\mathbf{i s}}\right)}_{\mathbf{b}_{\mathbf{i}}}+\underbrace{\mathbf{d}_{\mathbf{h}} \cdot\left(\frac{1+\cos \left(\vartheta_{\mathrm{i}}\right)}{2}\right)}_{\mathbf{d}_{\mathbf{i}}}+\underbrace{\mathbf{g}_{\mathbf{h}} \cdot \rho_{\mathrm{g}} \cdot\left(\frac{1-\cos \left(\vartheta_{\mathrm{i}}\right)}{2}\right)}_{\mathbf{g}_{\mathbf{g r}, \mathbf{i}}} \\
& =\mathbf{b}_{\mathbf{i}}+\mathbf{d}_{\mathbf{i}}+\mathbf{g}_{\mathbf{g r}, \mathbf{i}}
\end{aligned}
$$

where $\mathbf{b}_{\mathbf{i}}\left[\mathrm{W} / \mathrm{m}^{2}\right]$ is the direct beam, $\mathbf{d}_{\mathbf{i}}\left[\mathrm{W} / \mathrm{m}^{2}\right]$ is the sky diffuse and $\mathbf{g}_{\mathbf{g r}, \mathbf{i}}\left[\mathrm{W} / \mathrm{m}^{2}\right]$ is the ground reflected diffuse radiation present on the surface $i, \vartheta_{\mathrm{i}}\left[{ }^{\circ}\right]$ is the slope inclination. The ground reflectivity is given in Table C.7.

Under the assumption that the solar angles are known, the incidence angle of the solar beam with respect to an inclined surface $\boldsymbol{\lambda}_{\text {is }}$ can be calculated (Eq. 1.6.3 [57]) as follows.

$$
\begin{aligned}
\cos \left(\boldsymbol{\lambda}_{\mathbf{i}}\right) & =\cos \left(\boldsymbol{\vartheta}_{\mathbf{s}}\right) \cdot \cos \left(\vartheta_{\mathrm{i}}\right)+\sin \left(\boldsymbol{\vartheta}_{\mathbf{s}}\right) \cdot \sin \left(\vartheta_{\mathrm{i}}\right) \cdot \cos \left(\boldsymbol{\gamma}_{\mathbf{s}}-\boldsymbol{\gamma}_{\mathrm{i}}\right) \\
& =\sin \left(\boldsymbol{\alpha}_{\mathbf{s}}\right) \cdot \cos \left(\vartheta_{\mathrm{i}}\right)+\cos \left(\boldsymbol{\alpha}_{\mathbf{s}}\right) \cdot \sin \left(\vartheta_{\mathrm{i}}\right) \cdot \cos \left(\boldsymbol{\gamma}_{\mathbf{s}}-\boldsymbol{\gamma}_{\mathrm{i}}\right)
\end{aligned}
$$


Table C.7: Parameters to calculate incident radiation.

\begin{tabular}{llll}
\hline Parameter & Symbol & Value & Unit \\
\hline Ground reflectivity [58] & $\rho_{g}$ & 0.154 & - \\
\hline
\end{tabular}

\section{Appendix C.1. Solar thermal: flat plate collector (FP)}

The efficiency of solar thermal collectors at steady state conditions is commonly described by a quadratic performance curve that depends on the operating temperature $\mathrm{T}_{\mathrm{m}}^{\mathrm{FP}}=0.5 \cdot\left(\mathrm{T}_{\mathrm{in}}^{\mathrm{FP}}+\mathrm{T}_{\text {out }}^{\mathrm{FP}}\right)$, the incoming radiation intensity during that period $g_{p, i}\left[\mathrm{~W} / \mathrm{m}^{2}\right]$, the conversion factor $\eta_{0}^{\mathrm{FP}}$, and two experimental parameters $\mathrm{a}_{1}^{\mathrm{FP}}$ and $\mathrm{a}_{2}^{\mathrm{FP}}$.

The general conversion factor is defined by the absorber material, thickness, and heat transfer fluid flow characteristics. The first experimental coefficient is usually related to the collector convective heat losses, and the latter is influenced by the collector re-radiation losses. The temperature dependent efficiency Equation C.4 is then written as follows ([57] Eq. 6.17.7, 22]).

$$
\eta_{p}^{\mathrm{FP}}=\eta_{0}^{\mathrm{FP}}-\mathrm{a}_{1}^{\mathrm{FP}} \cdot \frac{\mathrm{T}_{\mathrm{m}}^{\mathrm{FP}}-\mathrm{T}_{p, \mathrm{a}}}{\mathrm{g}_{p, \mathrm{i}}}-\mathrm{a}_{2}^{\mathrm{FP}} \cdot \mathrm{g}_{p, \mathrm{i}} \cdot\left(\frac{\mathrm{T}_{\mathrm{m}}^{\mathrm{FP}}-\mathrm{T}_{p, \mathrm{a}}}{\mathrm{g}_{p, \mathrm{i}}}\right)^{2} \quad \forall p \in \mathbf{P}
$$

All parameters can be found in Table C.8. The formula accounts for a reduction in efficiency for operating temperatures higher than the ambient (due to thermal losses) and for reduction in efficiency due to reduced radiation intensities at normal incidence. However, since panels are installed at a fixed position, an incidence angle modifier is introduced in order to account for optical losses related to the angle of the incident radiation. By definition, it is set to one at $0^{\circ}$ incidence and is usually provided at $50^{\circ}$. In order to find other data points a cosine law is traditionally suggested (e.g. 6.17.10 [57] also in ASHRAE 93-2003), which however cannot be evaluated for angles close to $90^{\circ}$. Therefore an Ambrosetti type Equation [59] is used here which can be evaluated up to $90^{\circ}$.

$$
\mathrm{f}_{\mathrm{IAM}}^{\mathrm{FP}}(\lambda)=1-\tan ^{\mathrm{a}}\left(\frac{\lambda}{2}\right)
$$

where the coefficient a here provided in Table C.8 is usually derived from known data at a certain inclination (e.g. $\left.50^{\circ}\right)$; for beam radiation, the incidence angle $\lambda$ is equivalent to the solar angle of incidence on the slope $\lambda_{\text {is }}\left[^{\circ}\right]$. For the diffuse and ground reflected component, the incidence angle is found from Equation (C.6) based on the slope inclination $\vartheta_{\mathrm{i}}^{\mathrm{FP}}$ ([57, Figure 5.4.1, Eq. 5.4.1, 5.4.2).

$$
\begin{aligned}
& \lambda_{\text {id }}=90-0.5788 \cdot \vartheta_{\mathrm{i}}^{\mathrm{FP}}+0.002693 \cdot\left(\vartheta_{\mathrm{i}}^{\mathrm{FP}}\right)^{2} \\
& \lambda_{\text {igr }}=59.7-0.1388 \cdot \vartheta_{\mathrm{i}}^{\mathrm{FP}}+0.001497 \cdot\left(\vartheta_{\mathrm{i}}^{\mathrm{FP}}\right)^{2}
\end{aligned}
$$

With this, the time-dependent thermal energy production $\mathrm{Q}_{p}^{\mathrm{FP}}[\mathrm{W}]$ of the solar flat plate collectors can be formulated.

$$
\mathrm{Q}_{p}^{\mathrm{FP}}=\eta_{p}^{\mathrm{FP}} \cdot \mathrm{f}_{\mathrm{field}}^{\mathrm{FP}} \cdot\left(\mathrm{b}_{p, \mathrm{i}} \cdot \mathrm{f}_{p, \mathrm{IAM}, \mathrm{ib}}^{\mathrm{FP}}+\mathrm{d}_{p, \mathrm{i}} \cdot \mathrm{f}_{\mathrm{IAM}, \mathrm{id}}^{\mathrm{FP}}+\mathrm{g}_{p, \mathrm{gr}, \mathrm{i}} \cdot \mathrm{f}_{\mathrm{IAM}, \mathrm{ir}}^{\mathrm{FP}}\right) \cdot \mathrm{A}^{\mathrm{FP}} \quad \forall p \in \mathbf{P}
$$

where each type of radiation (direct beam $b_{p, i}$, sky diffuse $d_{p, i}$, ground reflected diffuse $g_{p, g r, i}$ ) is multiplied with the respective incidence angle modifier Eq. C.5 C.6), the collector area, thermal field loss factor (Table C.8 and efficiency from Eq. C.4.

Performance. Figure C.16 shows the thermal conversion efficiency $\eta_{p \text {,tot }}^{\mathrm{FP}}=\mathrm{Q}_{p}^{\mathrm{FP}} /\left(\mathrm{g}_{\mathrm{h}, p} * \mathrm{~A}^{\mathrm{FP}}\right)$ of the thermal energy production of a flat plate collector $\mathrm{Q}_{p}^{\mathrm{FP}}$ in period $p$ with respect to the global horizontal radiation $\mathrm{g}_{\mathrm{h}, p}$ in each period $p$. This efficiency is comprised of not only the conductive and radiative thermal losses, but also the losses caused by the non-perpendicular angle of incidence of the sun. Since the collectors are installed in a fixed position, different angles of inclination need to be tested. The graph indicates clearly 


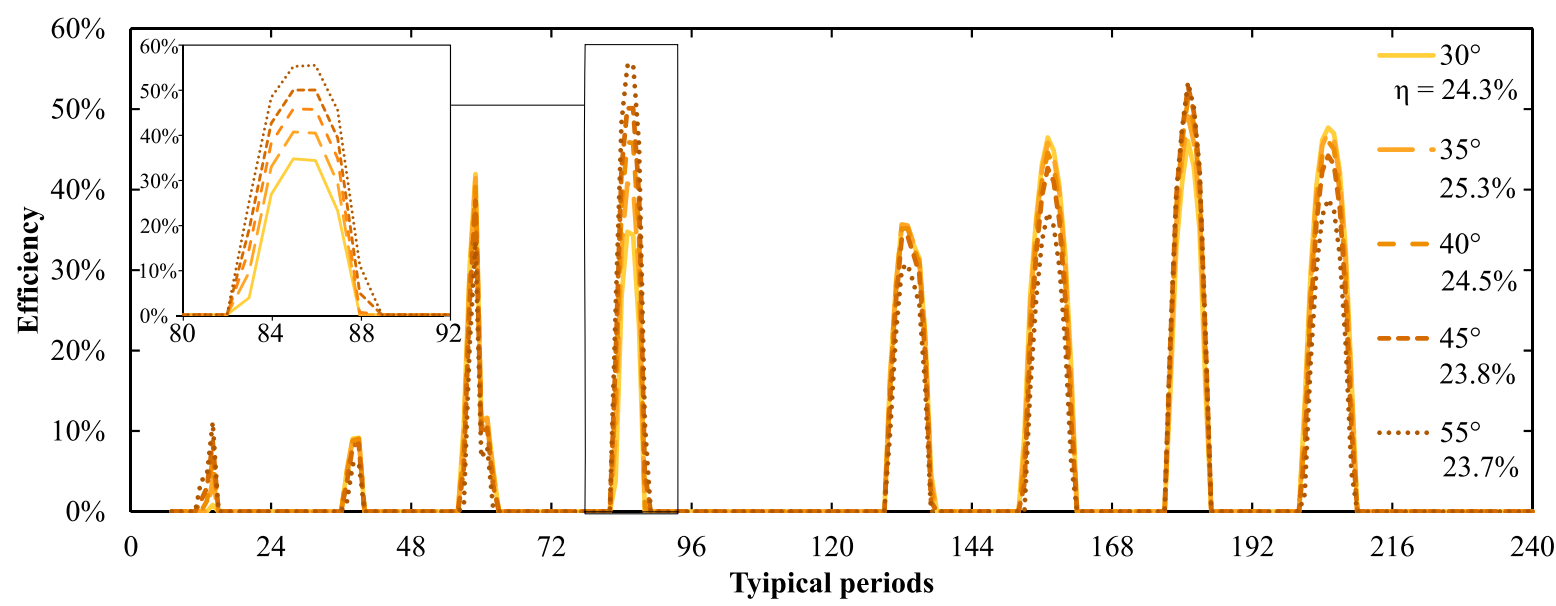

Figure C.16: Thermal conversion efficiency of flat plate (FP) solar thermal collectors as a function of time for different inclination angles, performance equations presented in Appendix C.1

that in some days (e.g. day number four and eight) collectors with $55^{\circ}$ inclination outperform the collectors with smaller inclination angles. This stems from the fact that on these (winter) days the solar elevation angle is not very high (see Figure 5) and collectors installed at higher inclination can capture more of the incoming radiation. On days in the middle of the summer (e.g. day number seven and nine), the solar elevation angle is very high and therefore the collectors with the smallest inclination angles exhibit the best performance. In the end, the total yearly performance is the most important indicator which is displayed in Figure C.16 for all the inclination angles. It is weighted by the relative occurrence of each typical period in the year. An inclination angle of $35^{\circ}$ with an overall efficiency of about $25.3 \%$ exhibits the best performance and was therefore chosen for further analysis.

This average efficiency of the considered flat plate collectors is far below the theoretical maximum of up to $60 \%$. In this study a balance is struck between performance and capital investment. The efficiency of single glazed flat plate thermal collectors drops with higher operating temperatures, lower ambient temperatures, and the inclination of the sun. These insufficiencies are partly overcome by better insulation or by changing the collector model (e.g. evacuated tube collectors). Both of these options come at distinctly higher costs

Table C.8: Flat plate solar collector (FP) parameters, if no other indication, data taken for single glazing flat plate collectors from Tehnomont 60] data tested by SPF [29].

\begin{tabular}{llll}
\hline Parameter & Symbol & Value & Unit \\
\hline Ground reflectivity & $\rho_{\mathrm{g}}$ & 0.154 & - \\
Heat transfer fluid & & water glycol mix & \\
Investment cost $([29,2012)$ & $\mathrm{IV}_{\mathrm{FP}}$ & 196 & $€ / \mathrm{m}^{2}$ \\
Installation cost factor & $\mathrm{f}_{\mathrm{FP}}$ & 1.5 & - \\
Total investment $\{$ min,max $\}$ & & $\{200,600\}$ & $€ / \mathrm{m}^{2}$ \\
Collector area & $\mathrm{A}^{\mathrm{FP}}$ & 2.059 & $\mathrm{~m}^{2}$ \\
Standard efficiency/ conversion factor & $\eta_{0}^{\mathrm{FP}}$ & 0.74 & - \\
Efficiency coefficient 1 & $\mathrm{a}_{1}^{\mathrm{FP}}$ & 3.5940 & $\mathrm{~W} / \mathrm{m}^{2} \mathrm{~K}$ \\
Efficiency coefficient 2 & $\mathrm{a}_{2}^{\mathrm{FP}}$ & 0.00864 & $\mathrm{~W} / \mathrm{m}^{2} \mathrm{~K}^{2}$ \\
Incidence angle modifier coefficient & $\mathrm{a}$ & 2.40 & - \\
Fluid inlet temperature & $\mathrm{T}_{\text {in }}^{\mathrm{FP}}$ & 80 & $\mathrm{C}$ \\
Fluid outlet temperature & $\mathrm{T}_{\text {out }}^{\mathrm{FP}}$ & 105 & $\mathrm{C}$ \\
Slope Inclination (recommended: similar to latitude) & $\vartheta_{\mathrm{i}}^{\mathrm{FP}}$ & 35 & $\circ$ \\
Azimuth, shift towards south & $\gamma_{\mathrm{i}}^{\mathrm{FP}}$ & 0 & $\circ$ \\
Thermal field loss factor & $\mathrm{f}_{\text {field }}^{\mathrm{FP}}$ & 0.97 & - \\
\hline
\end{tabular}


(factor 2 and higher [29]) and were, therefore, not considered.

\section{Appendix C.2. Photovoltaic module (PV)}

As mentioned before, the two main parameters influencing the PV performance is the cell temperature and the irradiation intensity. The cell temperature can be determined by correlations found in the literature (Eq. 23.3.4 [57]).

$$
\mathrm{T}_{p, \mathrm{c}}^{\mathrm{PV}}=\mathrm{T}_{p, \mathrm{a}}+\frac{\mathrm{g}_{p, \mathrm{i}}}{\mathrm{g}_{\mathrm{NOCT}}} \cdot \frac{9.5}{5.7+3.8 \cdot \mathrm{v}_{p, \mathrm{a}}} \cdot\left[1-\frac{\eta_{\mathrm{m}}^{\mathrm{PV}}}{(\tau \alpha)}\right] \cdot\left(\mathrm{T}_{\mathrm{NOCT}}^{\mathrm{PV}}-\mathrm{T}_{\mathrm{a}, \mathrm{NOCT}}\right) \quad \forall p \in \mathbf{P}
$$

where $\mathrm{T}_{p, \mathrm{a}}$ is the (time dependent) ambient temperature, $\mathrm{v}_{p, \mathrm{a}}$ is the ambient wind speed, and $\mathrm{g}_{p, i}$ is the global incident radiation on an inclined surface during period $p$ (see Appendix C). The irradiation and ambient temperature at nominal operating cell temperature (NOCT) conditions as well as all other parameters are depicted in Table C.9. The ambient temperature and wind speed are provided from the meteorological data described in Section 2.1.2.

A factor accounting for the influence of the incident radiation intensity is calculated by linear interpolation between the standard testing conditions (STC, see Table C.9) and the certified indication at 200W/ $\mathrm{m}^{2}$.

$$
\mathrm{f}_{p, \mathrm{~g}}^{\mathrm{PV}}=\mathrm{f}_{200}+\left(\mathrm{g}_{p, \mathrm{i}}-\mathrm{g}_{200}\right) \cdot \frac{1-\mathrm{f}_{200}}{\mathrm{~g}_{\mathrm{STC}}-\mathrm{g}_{200}} \quad \forall p \in \mathbf{P}
$$

The time-dependent electricity production $\mathrm{E}_{p}^{\mathrm{PV}}[\mathrm{W}]$ is then written according to the following (Eq. 23.2.16 [57]).

$$
\mathrm{E}_{p}^{\mathrm{PV}}=\eta_{\mathrm{m}}^{\mathrm{PV}} \cdot \mathrm{f}_{\mathrm{gen}}^{\mathrm{PV}} \cdot \mathrm{f}_{p, \mathrm{~g}}^{\mathrm{PV}} \cdot\left[1-\mathrm{f}_{\mathrm{T}}^{\mathrm{PV}} \cdot\left(\mathrm{T}_{p, \mathrm{c}}^{\mathrm{PV}}-\mathrm{T}_{\mathrm{STC}}^{\mathrm{PV}}\right)\right] \cdot \mathrm{g}_{p, \mathrm{i}} \cdot \mathrm{A}^{\mathrm{PV}} \quad \forall p \in \mathbf{P}
$$

where all parameters such as the module area, the temperature reduction factor, and the electrical conversion factor are depicted either in Table C.9 or in the Equations above.

Table C.9: Photovoltaic module (PV) parameters, if no other indication, data taken from [31. Nominal Cell Operating Temperature (NOCT) are a set of conditions which are defined in order to find the nominal cell operating temperature. Standard Testing Conditions (STC) are at $1000 \mathrm{~W} / \mathrm{m}^{2}, 25^{\circ} \mathrm{C}$ cell temperature and air mass 1.5.

\begin{tabular}{llll}
\hline Parameter & Symbol & Value & Unit \\
\hline Investment cost [61] & $\mathrm{IV}^{\mathrm{PV}}$ & 260 & $€ / \mathrm{m}^{2}$ \\
Installation cost factor & $\mathrm{f}_{\mathrm{FP}}$ & 1.5 & - \\
Total investment $\{$ min,max $\}$ & & $\{300,800\}$ & $€ / \mathrm{m}^{2}$ \\
Maximum power & & 290 & $\mathrm{~W}$ \\
Module area & $\mathrm{A}^{\mathrm{PV}}$ & 1.63 & $\mathrm{~m}^{2}$ \\
Module efficiency & $\eta_{\mathrm{m}}^{\mathrm{PV}}$ & 0.178 & - \\
Temperature reduction factor & $\mathrm{f}_{\mathrm{T}}^{\mathrm{PV}}$ & 0.004 & $-/ \mathrm{K}$ \\
Efficiency reduction at $\mathrm{g}_{200}=200 \mathrm{~W} / \mathrm{m}^{2}$ & $\mathrm{f}_{200}$ & 0.98 & - \\
STC radiation & $\mathrm{g}_{\mathrm{STC}}$ & 1000 & $\mathrm{~W} / \mathrm{m}^{2}$ \\
Nominal Operating Cell Temperature & $\mathrm{T}_{\mathrm{NOCT}}$ & 45 & ${ }^{\circ} \mathrm{C}$ \\
NOCT radiation & $\mathrm{g}_{\mathrm{NOCT}}$ & 800 & $\mathrm{~W} / \mathrm{m}^{2}$ \\
NOCT ambient temperature & $\mathrm{T}_{\mathrm{a}, \mathrm{NOCT}}$ & 20 & ${ }^{\circ} \mathrm{C}$ \\
NOCT wind speed & $\mathrm{v}_{\mathrm{a}, \mathrm{NOCT}}$ & 1 & $\mathrm{~m} / \mathrm{s}$ \\
Inclination (around latitude) & $\vartheta_{\mathrm{i}}^{\mathrm{PV}}$ & 30 & ${ }^{\circ}$ \\
Azimuth, shift towards south & $\gamma_{\mathrm{i}}^{\mathrm{PV}}$ & 0 & ${ }^{\circ}$ \\
Effective transmittance-absorptance product & $\mathrm{\tau}^{\mathrm{P}}$ & 0.9 & - \\
Electrical conversion factor & $\mathrm{f}_{\mathrm{gen}}^{\mathrm{PV}}$ & 0.95 & - \\
\hline
\end{tabular}


Performance. Figure C.17 shows the conversion efficiency from the global horizontal irradiance (GHI) $\mathrm{g}_{p, \mathrm{i}}$ in each period $p$ to the electricity produced in the photovoltaic modules $\eta_{p, \text { tot }}^{\mathrm{PV}}=\mathrm{E}_{p}^{\mathrm{PV}} /\left(\mathrm{g}_{p, \mathrm{i}} \cdot \mathrm{A}^{\mathrm{PV}}\right)$, where $\mathrm{E}_{p}^{\mathrm{PV}}$ is the electrical production of a $\mathrm{PV}$ module in period $p$. As discussed previously, the GHI only covers the fraction of the solar radiation that hits the earth at a perpendicular angle. This allows the conversion efficiency (if it is described in this manner) to exceed the rated efficiency of the PV modules (e.g. on day 1), since the inclined modules may capture more of the inclined sun rays than the GHI takes into account. The assessment also changes if shadowing is taken into account, though this was not considered as a factor in this study. The winter days $(1,4$, and 9$)$ show due to this peculiarity and due to lower ambient temperatures the highest efficiencies. In agreement with the observation from the plate collectors, it can be seen that higher inclinations are favored in winter days while lower inclination angles perform better during summer days. The highest overall efficiency is found for the lowest inclination angle of $30^{\circ}$ with an average of $18.1 \%$. Such efficiencies may only be reached for high performance PV modules such as the ones assumed. More detailed modeling, considering shading and conversion losses, will most likely show lower performance values.

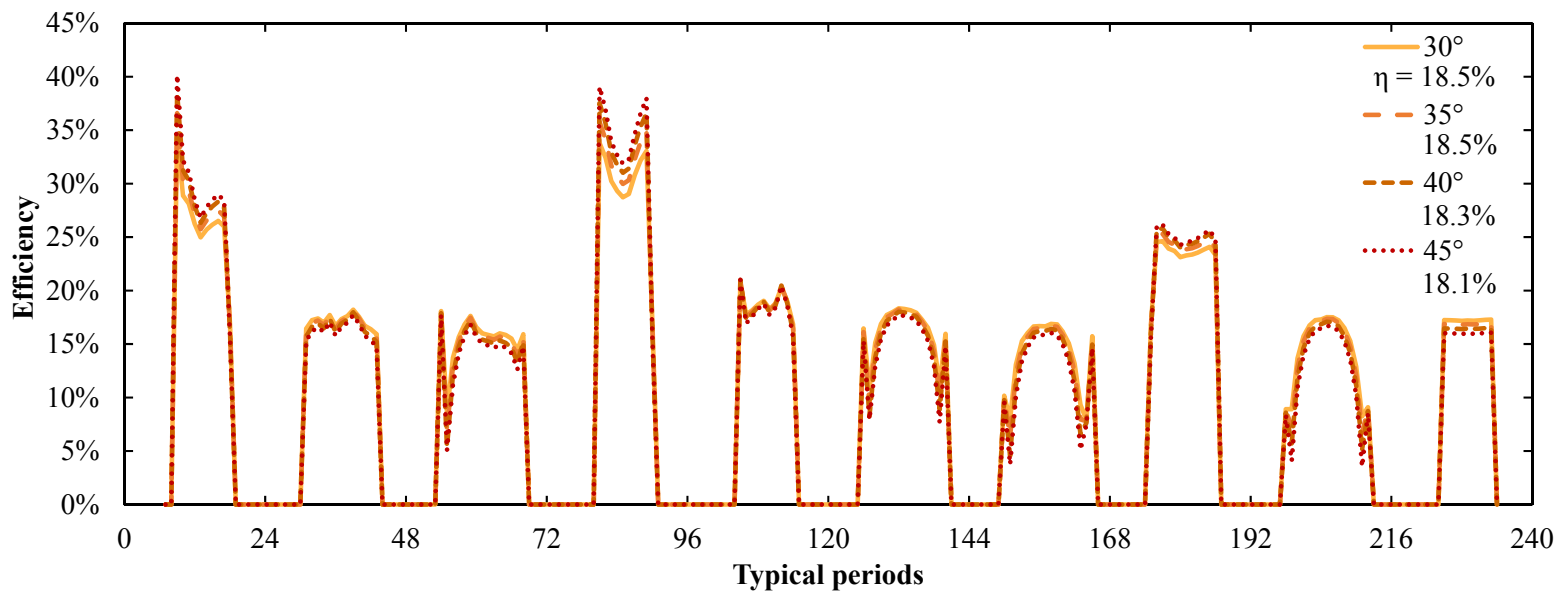

Figure C.17: Electrical conversion efficiency of photovoltaic modules (PV) solar thermal collectors as a function of time for different inclination angles, input data presented in Appendix C.2

\section{Appendix C.3. Photovoltaic and thermal (HCPVT)}

High concentration devices only convert direct beam radiation. Performance indicators are retrieved from the producer 32 35. Due to the high concentration ratio, the efficiency is assumed to be independent of the incident radiation intensity and due to the two axis tracking the angle of incidence is always zero. The time-dependent electricity $\mathrm{E}_{p}^{\mathrm{HCPVT}}[\mathrm{W}]$ and thermal energy production $\mathrm{Q}_{p}^{\mathrm{HCPVT}}[\mathrm{W}]$ is formulated according to the following.

$$
\begin{aligned}
& \mathrm{E}_{p}^{\mathrm{HCPVT}}=\mathrm{f}_{\mathrm{gen}}^{\mathrm{HCPVT}} \cdot \eta_{\mathrm{el}}^{\mathrm{HCPVT}} \cdot \mathrm{b}_{p, \mathrm{n}} \cdot \mathrm{A}^{\mathrm{HCPVT}} \forall p \in \mathbf{P}
\end{aligned}
$$

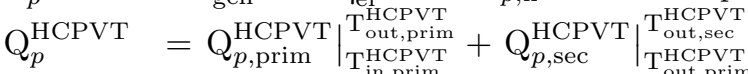

$$
\begin{aligned}
& =\mathrm{f}_{\text {field }}^{\mathrm{HCPVT}} \cdot\left(\eta_{\mathrm{th}, \text { prim }}^{\mathrm{HCPVT}}+\eta_{\mathrm{th}, \mathrm{sec}}^{\mathrm{HCPVT}}\right) \cdot \mathrm{b}_{p, \mathrm{n}} \cdot \mathrm{A}^{\mathrm{HCPVT}} \forall p \in \mathbf{P}
\end{aligned}
$$

where $\mathrm{b}_{p, \mathrm{n}}$ is the direct beam normal radiation in period $p$, all further parameters are presented in Table C.10. The primary efficiency $\eta_{\mathrm{th} \text {,prim }}^{\mathrm{HCPVT}}$ stems from the PV cell cooling while the secondary efficiency $\eta_{\mathrm{th} \text {,sec }}^{\mathrm{HCPVT}}$ is derived from the cooling of the secondary concentrators positioned immediately prior to the receiver. The PV cell cooling is constrained by the cell temperature which should not exceed $100^{\circ} \mathrm{C}$; therefore, the cooling stream cannot reach temperatures higher than $95^{\circ} \mathrm{C}$. The secondary cooling, contrary to the restriction imposed for the primary PV cooling, can reach any superheating temperature. Therefore, two thermal streams are produced which are between the three temperatures $\mathrm{T}_{\text {in,prim }}^{\mathrm{HCPVT}}, \mathrm{T}_{\text {out,prim }}^{\mathrm{HCPVT}}$, and $\mathrm{T}_{\text {out,sec }}^{\mathrm{HCPVT}}$. The average 
yearly overall efficiency of the HCPVT system with respect to the DNI is $24 \%_{\text {el }}$ and $55 \%_{\text {th }}$, respectively, which is extremely high and may be overestimated.

Table C.10: High concentration photovoltaic and thermal system (HCPVT) parameters, data taken from 32 .

\begin{tabular}{llll}
\hline Parameter & Symbol & Value & Unit \\
\hline Heat transfer fluid & & water glycol mix & \\
Investment cost & $\mathrm{IV}^{\mathrm{HCPVT}}$ & 700 & $€ / \mathrm{m}^{2}$ \\
Dish area & $\mathrm{A}^{\mathrm{HCPVT}}$ & 40.05 & $\mathrm{~m}^{2}$ \\
Installation cost factor & $\mathrm{f}_{\mathrm{FP}}$ & 1.5 & - \\
Total investment $\{$ min,max $\}$ & & $\{500,1500\}$ & $€ / \mathrm{m}^{2}$ \\
Primary efficiency & $\eta_{\mathrm{th}, \mathrm{prim}}^{\mathrm{HCPVT}}$ & 0.5 & - \\
Secondary efficiency & $\eta_{\mathrm{th}, \text { sec }}^{\mathrm{HeC}}$ & 0.05 & - \\
Electrical efficiency & $\eta_{\mathrm{el}}^{\mathrm{HCPVT}}$ & 0.25 & - \\
Fluid temperature primary in & $\mathrm{T}_{\text {in,prim }}^{\mathrm{HCPPT}}$ & 85 & ${ }^{\circ} \mathrm{C}$ \\
Fluid temperature primary out & $\mathrm{T}_{\text {out,prim }}^{\mathrm{HCPV}}$ & 92 & ${ }^{\circ} \mathrm{C}$ \\
Fluid temperature secondary out & $\mathrm{T}_{\text {out,sec }}^{\mathrm{HCPV}}$ & 110 & ${ }^{\circ} \mathrm{C}$ \\
Thermal field loss factor & $\mathrm{f}_{\text {fiep }}^{\mathrm{HCVT}}$ & 0.9 & - \\
Electrical conversion factor & $\mathrm{f}_{\text {gen }}^{\mathrm{HCPT}}$ & 0.9 & - \\
\hline
\end{tabular}

Performance. The HCPVT conversion efficiencies are not depicted here as they are assumed to be constant over time independent from the irradiance and other potentially influencing factors such as the ambient temperature (active cooling). The dish thermal efficiency is assumed to approximate $55 \%$, and the electrical efficiency $25 \%$. Constant electrical conversion losses and solar thermal losses in the field were considered in this study.

\section{Appendix C.4. Storage}

The MILP Equations of the storage are explained by Becker et al. [18, where the thermal storage mass and energy balances are formulated based on different temperature levels modeled as different interconnected tanks. The implementation relies on the mass storage presented by Moret et al. 62 which is expanded to represent the thermal behavior. The parameters of the sensible heat storage are presented in Table C.11.

The non-linear storage $\left[€ / \mathrm{m}^{3}, 2002\right]$ cost is taken from [63] where the volume $V$ is in $\mathrm{m}^{3}$, and an installation factor of 1.5 is assumed.

$$
\mathrm{IV}^{\mathrm{STO}}=1.5 * 18179 \cdot(\mathrm{V} \cdot 1000)^{-0.3653}
$$

The coefficients of the linearized, annualized, and actualized cost $I V^{\mathrm{STO}}=\mathrm{a}+\mathrm{b} * V$ are depicted in Table

Table C.11: Storage parameters.

\begin{tabular}{|c|c|c|c|}
\hline $\begin{array}{l}\text { Parameter } \\
\text { Storage tank }\end{array}$ & $\begin{array}{l}\text { Symbol } \\
\text { STO }\end{array}$ & Value & Unit \\
\hline Investment & $\mathrm{IV}^{\mathrm{STO}}$ & Eq. (C.12) & \\
\hline Constant investment cost coefficient & $a$ & $871 \square$ & $€ / \mathrm{a}$ \\
\hline Linear investment cost coefficient & $b$ & 67.5 & $€ / \mathrm{m}^{3} / \mathrm{a}$ \\
\hline Hot temperature (FP, HCPVT) & $\mathrm{T}_{\mathrm{h}}$ & 90,85 & ${ }^{\circ} \mathrm{C}$ \\
\hline Cold temperature & $\mathrm{T}_{\mathrm{c}}$ & 75 & ${ }^{\circ} \mathrm{C}$ \\
\hline Hourly thermal losses & & 0.1 & $\% / \mathrm{h}$ \\
\hline
\end{tabular}


Performance. Figure C.18 illustrates the thermal storage filling in addition to the boiler and solar dish behavior over a selected range of operating periods. The storage is charged when the availability of the sun exceeds the process requirements (at around $80 \%$ of its total potential) and is consumed with decreasing solar availability. It can be seen that the solar availability is increased by the storage or in other words that the boiler utilization is reduced due to the emptying of the tank, which indicates the advantage of the storage. For higher utilization of the storage, the $\varepsilon$-constraint would have to be decreased.

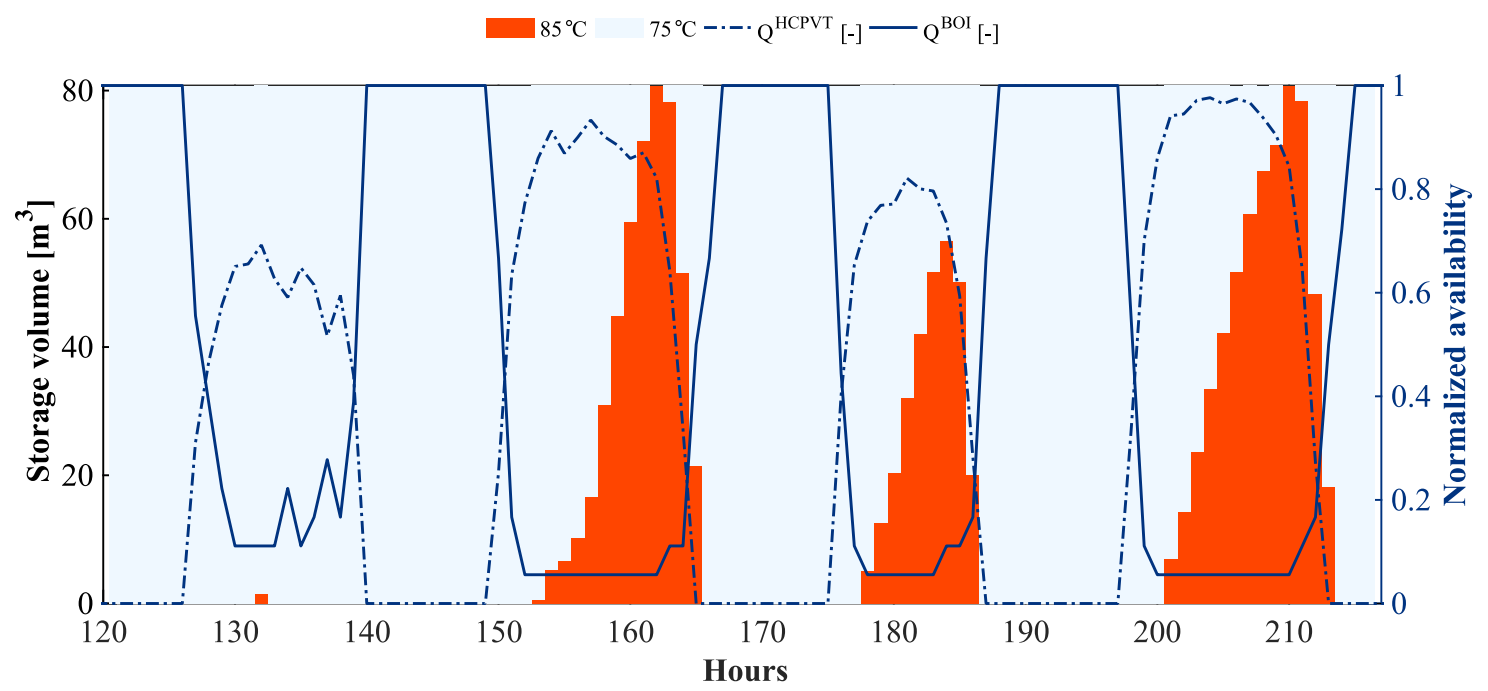

Figure C.18: Thermal storage volume and temperature distribution between typical day 6 and 9 with HCPVT solar dish and non-stop operation of the industrial process, case 2.4 . HCPVT $\mathrm{O}$ at $\varepsilon=70 \%$ of the 2 . HPS case. In dark blue: operation of boiler and solar dish normalized between $[0,1]$.

\section{Appendix D. Weather data \& clustering}

Follwoing the indications of Dominguez et al. 20 the typical days are built from n clusters with 2 extreme days. For clustering, 3 indicators are chosen which influence the solar performance the most: DNI, GHI, and the ambient temperature. Since the DNI fluctuates the most on an hourly, daily, and monthly basis with a high influence on the solar output, it is chosen as the main reference for determination of the performance indicator. Also the extreme days are determined based on the DNI, which means that one extreme day is found for the highest daily radiation and lowest solar radiation. In Figure 5 in the upper corner the typical days and their occurrence are illustrated. The two last days are extreme days which are represented only once. The operating time of one period is one hour which leads to 240 operating periods.

Table D.12 displays the yearly average values and mean squared error of the six weather data attributes of which only three are subject to the clustering. The yearly means of the three attributes that are used for clustering are very close to the original data and thus the error of the first three indicators is comparably small. Errors for the outside temperature and the wind speed, however, are distinctly higher. This may be explained by stronger fluctuations throughout the year even though the ambient temperature is used as input to the k-medoids clustering.

\section{Appendix E. Dairy process}

The process streams as discussed in [18, are depicted in Table E.13. 
Table D.12: Data of typical days compared to original.

\begin{tabular}{lllll}
\hline Attribute & Unit & Mean $_{\text {original }}$ & Mean $_{\text {typical }}$ & mELDC $10^{-4}$ \\
\hline GHI & {$\left[\mathrm{W} / \mathrm{m}^{2}\right]$} & 163.2 & 163.3 & 1.685 \\
DNI & {$\left[\mathrm{W} / \mathrm{m}^{2}\right]$} & 192.8 & 190.1 & 3.242 \\
Elevation $\alpha_{\mathrm{s}}$ & {$\left[^{\circ}\right]$} & 14.1 & 13.4 & 2.603 \\
Azimuth $\gamma_{\mathrm{s}}$ & $\left.{ }^{\circ}\right]$ & 44.4 & 45.2 & 5.592 \\
$\mathrm{~T}_{\mathrm{a}}$ & {$\left[{ }^{\circ} \mathrm{C}\right]$} & 10.7 & 10.5 & 51.321 \\
$\mathrm{v}_{\mathrm{a}}$ & {$[\mathrm{m} / \mathrm{s}]$} & 2.1 & 3.1 & 100.837 \\
\hline
\end{tabular}

Table E.13: Hot and cold streams of the dairy process, reproduced from Becker et al. [18].

\begin{tabular}{llllrrl}
\hline Unit & Name & $\begin{array}{l}\text { Tin } \\
{\left[{ }^{\circ} \mathrm{C}\right]}\end{array}$ & $\begin{array}{l}\text { Tout } \\
{\left[{ }^{\circ} \mathrm{C}\right]}\end{array}$ & $\begin{array}{r}\text { Heat load } \\
{[\mathrm{kW}]}\end{array}$ & $\begin{array}{r}\Delta T_{\min } / 2 \\
{\left[{ }^{\circ} \mathrm{C}\right]}\end{array}$ & Remarks \\
\hline Regrigeration & ref & 6.0 & 4.0 & 76.0 & 2.0 & refrigeration inlet milk \\
\hline Pasteurization & pasto1a & 4.0 & 66.0 & 2356.0 & 2.0 & preheating \\
& pasto2a & 66.0 & 86.0 & 676.4 & 2.0 & pasteurization milk \\
& pasto3a & 86.0 & 4.0 & 2773.2 & 2.0 & refrigeration milk \\
& pasto4a & 66.0 & 98.0 & 119.7 & 2.0 & pasteurization cream \\
& pasto5a & 98.0 & 4.0 & 351.6 & 2.0 & refrigeration cream \\
\hline Concentration & eva1 & 4.0 & 70.3 & 504.0 & 2.0 & preheating \\
& eva2 & 70.3 & 70.3 & 904.2 & 1.2 & evaporation 1.effect \\
& eva3 & 66.4 & 66.4 & 864.1 & 1.2 & evaporation 2.effect \\
& eva4 & 60.8 & 60.8 & 849.8 & 1.2 & evaporation 3.effect \\
& eva5 & 60.8 & 4.0 & 151.5 & 2.0 & refrigeration concentrated milk \\
& eva6 & 68.9 & 68.9 & 904.2 & 1.2 & condensation 1.effect \\
& eva7 & 65.9 & 65.9 & 864.1 & 1.2 & condensation 2.effect \\
& eva9 & 68.9 & 15.0 & 87.8 & 2.0 & condensation 3.effect \\
& eva10 & 65.9 & 15.0 & 80.8 & 2.0 & cooling condensates 1.effect \\
\hline Condensates cooling & eva8 & 60.1 & 60.1 & 849.8 & 1.2 & cooling condensates 2.effect \\
& eva11 & 60.1 & 15.0 & 69.7 & 2.0 & cooling condensates 3.effect \\
\hline Yoghurt production & yog1 & 4.0 & 94.0 & 1026.0 & 2.0 & heating \\
& yog2 & 94.0 & 10.0 & 957.6 & 2.0 & cooling \\
\hline Desert production & des1 & 4.0 & 90.0 & 817.0 & 2.0 & heating \\
& des2 & 90.0 & 70.0 & 190.0 & 2.0 & cooling \\
\hline Hot water & hw & 15.0 & 55.0 & 167.2 & 2.0 & hot water prodcution \\
\hline Cleaning in place & CIP1a & 58.7 & 70.0 & 188.6 & 2.0 & maintain temperature CIP1 \\
& CIP1b & 65.0 & 15.0 & 104.5 & 2.0 & recuperation waste heat CIP1 \\
& CIP2a & 67.5 & 80.0 & 209.5 & 2.0 & maintain temperature CIP2 \\
& CIP2b & 75.0 & 15.0 & 125.4 & 2.0 & recuperation waste heat CIP2 \\
\hline Fridge & frig & 5.0 & 5.0 & 300.0 & 2.0 & maintain storage temperature \\
\hline & & & & & &
\end{tabular}

